\title{
Biophysics, pathophysiology, and pharmacology of ion channel gating pores
}

\author{
Adrien Moreau ${ }^{1}$, Pascal Gosselin-Badaroudine ${ }^{1}$ and Mohamed Chahine ${ }^{1,2 *}$ \\ ' Centre de Recherche de L'Institut Universitaire en Santé Mentale de Québec, Quebec City, OC, Canada \\ 2 Department of Medicine, Université Laval, Quebec City, OC, Canada
}

\author{
Edited by: \\ Jean-François Desaphy, University \\ of Bari Aldo Moro, Italy \\ Reviewed by: \\ Mirko Baruscotti, University of \\ Milano, Italy \\ Sébastien Roger, University of \\ Tours, France \\ *Correspondence: \\ Mohamed Chahine, Centre de \\ Recherche de L'Institut Universitaire \\ en Santé Mentale de Québec, 2601 \\ Chemin de la Canardière, Quebec \\ City, G1J 2 G3 OC, Canada \\ e-mail: mohamed.chahine@ \\ phc.ulaval.ca
}

Voltage sensor domains (VSDs) are a feature of voltage gated ion channels (VGICs) and voltage sensitive proteins. They are composed of four transmembrane (TM) segments (S1-S4). Currents leaking through VSDs are called omega or gating pore currents. Gating pores are caused by mutations of the highly conserved positively charged amino acids in the S4 segment that disrupt interactions between the S4 segment and the gating charge transfer center (GCTC). The GCTC separates the intracellular and extracellular water crevices. The disruption of S4-GCTC interactions allows these crevices to communicate and create a fast activating and non-inactivating alternative cation-selective permeation pathway of low conductance, or a gating pore. Gating pore currents have recently been shown to cause periodic paralysis phenotypes. There is also increasing evidence that gating pores are linked to several other familial diseases. For example, gating pores in $\mathrm{Na}_{v} 1.5$ and $\mathrm{K}_{\mathrm{v}} 7.2$ channels may underlie mixed arrhythmias associated with dilated cardiomyopathy (DCM) phenotypes and peripheral nerve hyperexcitability (PNH), respectively. There is little evidence for the existence of gating pore blockers. Moreover, it is known that a number of toxins bind to the VSD of a specific domain of $\mathrm{Na}^{+}$channels. These toxins may thus modulate gating pore currents. This focus on the VSD motif opens up a new area of research centered on developing molecules to treat a number of cell excitability disorders such as epilepsy, cardiac arrhythmias, and pain. The purpose of the present review is to summarize existing knowledge of the pathophysiology, biophysics, and pharmacology of gating pore currents and to serve as a guide for future studies aimed at improving our understanding of gating pores and their pathophysiological roles.

Keywords: ion channels, voltage sensor domain, channelopathies, gating charge transfer center, sodium channels, omega pores

\section{INTRODUCTION}

In the late 1940s, Hodgkin and Huxley were the first to highlight the importance of ionic movements in cell excitability. They showed that the process was mediated by dedicated structures now known as ion channels (Hodgkin and Huxley, 1952). Thirty-two years later, the first voltage sensitive ion channel was cloned (Noda et al., 1984). To date, at least 140 similar structures have been identified and assigned to the voltage gated ion channel (VGIC) superfamily (Yu and Catterall, 2004). Most of these VGICs (113 of 140) feature a voltage sensor domain (VSD) and thus belong to the VSD-featuring protein superfamily (Figure 1). Two structures are very common in this superfamily: the pore domain (PD) and the VSD. Based on ion selectivity, functional similarities, and structural homology, this superfamily can be divided into five main types: proteins lacking a PD, voltage gated sodium and calcium channels $\left(\mathrm{Na}_{\mathrm{v}}, \mathrm{Ca}_{\mathrm{v}}\right)$, voltage gated potassium channels $\left(\mathrm{K}_{\mathrm{v}}\right)$, cyclic nucleotide gated channels $(\mathrm{CNG})$, and transient receptors potential channels (TRPs).

The PD motif is present in channels that require the assembly of four VSD and PD motifs to form functional units. The $\mathrm{PD}$ is composed of two transmembrane (TM) segments and a re-entrant pore loop that links the segments (Figure 1). The assembly of four independent motifs forms tetrameric units that are frequently found in $\mathrm{K}_{\mathrm{v}}, \mathrm{CNG}$, and bacterial $\mathrm{Na}_{\mathrm{v}}$ channels. The assembly of four motifs into four domains of the same protein (DI to DIV) is a characteristic of mammalian $\mathrm{Na}_{\mathrm{v}}$ and $\mathrm{Ca}_{\mathrm{v}}$ channels (Figure 1). The two-pore channels (TPC) sub-family should be treated as an exception since it requires the assembly of only two units to form a functional unit. Each unit features two domains that assemble as a dimer to create a functional channel. The assembly of four PD motifs creates a permeation pathway that is responsible for the passage of ions from one side of the membrane to the other. The ionic selectivity of the channels is mainly provided by four to five highly conserved amino acids in the PD of $\mathrm{Na}_{\mathrm{v}}, \mathrm{Ca}_{\mathrm{v}}$, and $\mathrm{K}_{\mathrm{v}}$ channels [DEKA, EEDD, and (T/S)XG(Y/F)G, respectively] (Heinemann et al., 1992; Doyle et al., 1998; Valiyaveetil et al., 2006).

VSDs are composed of four TM segments (S1-S4) (Figure 1) and are present in most VGICs and in a few other proteins such as the voltage gated proton channel $\left(\mathrm{H}_{\mathrm{v}} 1\right)$ and TPTE. These proteins do not require the assembly of four domains to create a functional unit. To date, only the $\mathrm{H}_{\mathrm{v}} 1$ and TPTE proteins 


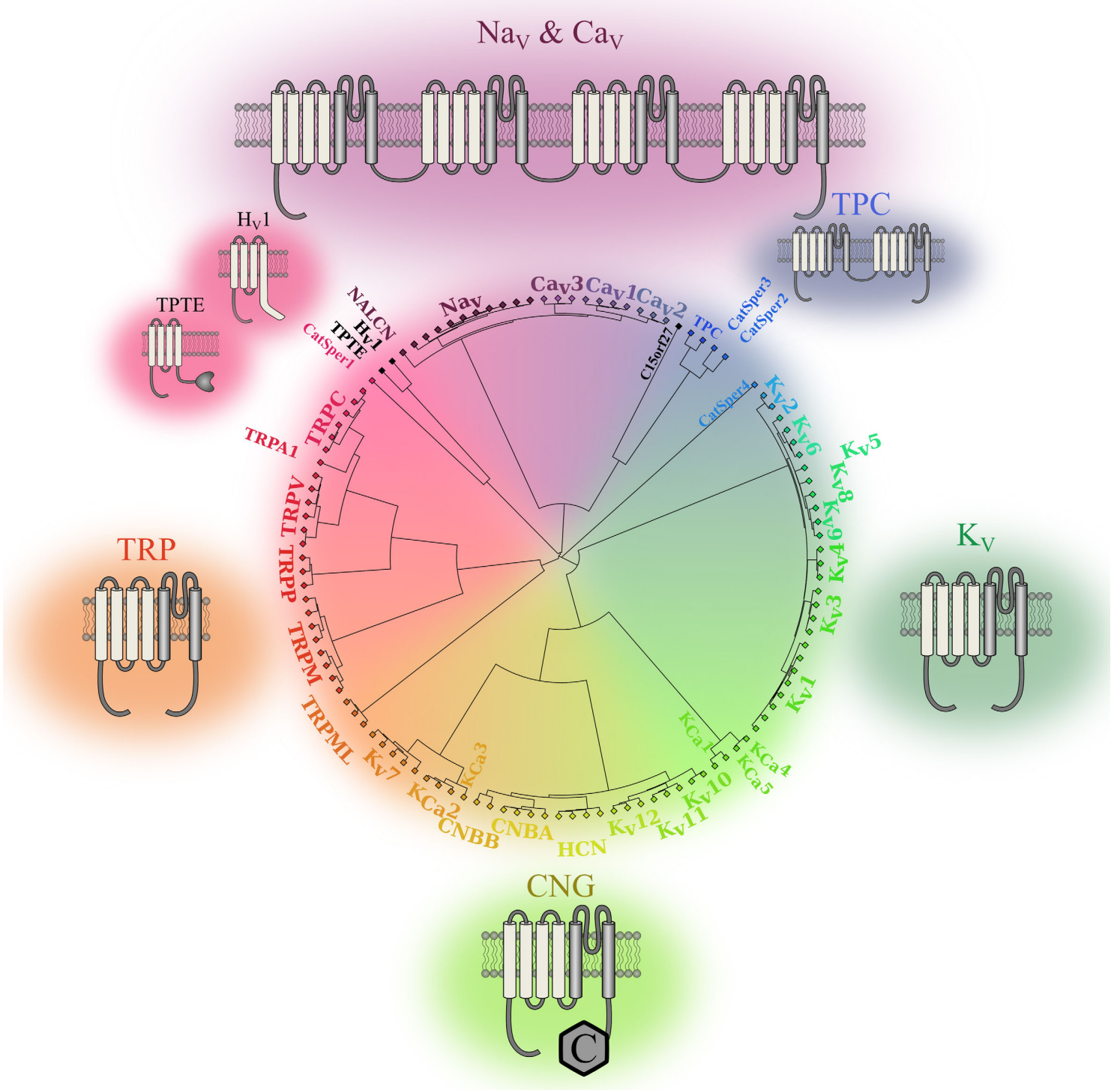

FIGURE 1 | Phylogenic representation of the VSD-featuring protein superfamily. The relationships between the amino acid sequences of various human proteins that feature one or more VSD motifs are represented as a circular phylogenic tree. The proteins are from the VGIC family (Yu and Catterall, 2004). Channels that do not feature a VSD motif were eliminated while proteins known to feature a VSD motif were included (Iwasaki et al., 2008; Musset et al., 2011). The complete sequences for each protein were aligned using Clustal Omega (Sievers et al., 2011). The phylogenic tree was then created using a custom Matlab script using the single linkage method. It highlights the five subgroups of the human VSD-featuring protein superfamily. $\mathrm{Na}_{\vee}$ and $\mathrm{Ca}_{\vee}$ channels are in shades of purple. These proteins have a VSD motif in each of their four homologous domains. TPCs are in blue. The fact that they feature a VSD motif in their two homologous domains sets them apart from the other members of the VSD-featuring protein superfamily. The structures of $K_{v}$ channels are in dark green. Since some of these channels share structural similarities with calcium-activated potassium channels $\left(K_{\mathrm{Ca}}\right)$ channels and CNG channels, the $K_{v} 7, K_{v} 10, K_{v} 11$, and $K_{v} 12$ channels were placed next to the $\mathrm{CNG}$ and $\mathrm{K}_{\mathrm{Ca}}$ families. The structures of the $\mathrm{CNG}$ and $\mathrm{K}_{\mathrm{Ca}}$ families are in light green, while the structures of TRP channels are in orange. Members of the PD-lacking group of proteins are in black. The 2-D structures show the VSDs in light gray and the PDs in dark gray. have been assigned to the category of proteins that do not feature a PD motif. However, the C15orf27 protein, which may contain a VSD, could likely be added to this category (Musset et al., 2011). Even if this category of proteins does not contain many members, studying it may lead to the discovery of similar proteins that play important physiological roles (Capasso et al., 2011).
The voltage sensitivity of the VSD-featuring channel and protein superfamily is provided by the interaction of several highly conserved charged residues. The S4 segment contains at least three positively charged residues (arginines and lysines) (Figure 2) while the S1, S2, and S3 segments contain organized structures of highly conserved negatively charged amino acids (aspartate and glutamate) as well as highly conserved aromatic 


\begin{tabular}{|c|c|c|c|c|c|}
\hline & \multirow[t]{2}{*}{ S1 } & \multicolumn{2}{|l|}{$\mathrm{S} 2$} & S3 & S4 \\
\hline & & \multicolumn{2}{|l|}{ F1 F2 E1 } & D1 & $\begin{array}{lllllll}\text { R0 } & \text { R1 } & \text { R2 } & \text { R3 } & \text { R4 } & \text { R5 } & \text { R6 }\end{array}$ \\
\hline Shaker & AARVVAI ISVFVILLSIVIFCL & \multicolumn{2}{|c|}{ LIETLCI IWETFELTVRFLA } & DVMNVIDIIAIIPYFITLATVVA & LRVIRLVRVFRIFKLSRHSKGL \\
\hline hHv1 & SSHRFQVIIICLVVLDALLVLA & \multicolumn{2}{|c|}{ YMS ITILVFFMME I IFKLFV } & HKEEILDAVVVVVSFILDIVLLF & LILLRLWRVARIINGIIISVKT \\
\hline C15orf27 & LSASLNSELVACVILVVILLTL & \multicolumn{2}{|c|}{ WISLVILSVEFSETVLRIVV } & NKIEVFDGAVI ILSLAPMVASTV & I IMLRIWRVKRVIDAYVLPVKL \\
\hline $\mathrm{K}_{\mathrm{v}} 7.1$ & V-YHFAVFLIVLVCLIFSVLST & \multirow{2}{*}{\multicolumn{2}{|c|}{$\begin{array}{l}\text { WME IVLVVFFGTEYVVRLWS } \\
\text { TLDYVCVAFFTFDILIRVCV }\end{array}$}} & KPISIIDLIVVVASMVVLCVGSK & IRGIRFLQI LRMLHVDRQGGTW \\
\hline N.at- $\mathrm{K}_{\mathrm{v}} 3.2$ & DKPSSSKGAFLYGVIVAVFVFL & & & SPMTVIEIIAVIPYYIDFVSHFI & IHVERIFGI LRVEKI LRHYSGL \\
\hline $\mathrm{Na}_{\mathrm{v}} 1.4 \mathrm{DI}$ & IHALFSMFIMITILTNCVFMTM & \multicolumn{2}{|c|}{ NVEYTETGIYTFESLIKILA } & DPWNWLDFSVIMMAYLTEFVDLG & ISALRTFRVLRALKTITVIPGL \\
\hline $\mathrm{Na}_{\mathrm{v}} 1.5 \mathrm{DI}$ & VHSLFNMLIMCTILTNCVFMAQ & \multicolumn{2}{|c|}{ YVEYTETAIYTFESLVKILA } & DPWNWLDFSVIIMAYTTEFVDLG & VSALRTERVLRALKTISVISGL \\
\hline $\mathrm{Ca}_{\mathrm{v}} 1.1 \mathrm{DI}$ & EWKPFETI ILLTIFANCVALAV & \multicolumn{2}{|c|}{ KLEYFFLIVFS IEAAMKI I A } & SGWNVLDETIVFLGVFTVILEQV & VKALRAFRVLRPLRLVSGVPSL \\
\hline $\mathrm{Na}_{\mathrm{v}} 1.4$ DII & MDPFVDLGITICIVLNTLFMAM & \multicolumn{2}{|c|}{ VGNLVETGIFTAEMVLKLIA } & QGWNIFDSIIVTLSLVELGLANV & LSVLRSFRLLRVFKLAKSWPTL \\
\hline $\mathrm{Na}_{\mathrm{v}} 1.5 \mathrm{DII}$ & MDPFTDLTITMCIVLNTLFMAL & \multicolumn{2}{|c|}{ VGNLVETGIFTAEMTFKI IA } & QGWNIFDSI IVILSLMELGLSRM & LSVLRSFRLLRVFKLAKSWPTL \\
\hline$C a_{\mathrm{v}} 1.1$ DII & KSKVFYWLVILIVALNTLSIAS & \multicolumn{2}{|c|}{ IANRVLLSLFTTEMLMKMYG } & SIFNRFDCFVVCSGILEILLVES & ISVLRCIRLIRIFKITKYWTSL \\
\hline $\mathrm{Na}_{\mathrm{v}} 1.4$ DIII & EHNWEETEIVFMILLSSGALAF & \multicolumn{2}{|c|}{ YADKVETYIFIMEMLIKWWA } & NAWCWLDFLIVDVSI I SLVANWL & IKSLRTLRALRPLRALSRFEGM \\
\hline $\mathrm{Na}_{\mathrm{v}} 1.5$ DIII & EHSWFETEI IFMILLSSGALAF & \multicolumn{2}{|c|}{ YADKMETYVEVLEMLIKWVA } & NAWCWLDFLIVDVSLVSLVANTL & IKSLRTLRALRPLRALSRFEGM \\
\hline $\mathrm{Ca}_{\mathrm{v}} 1.1$ DIII & NATWETNE I LLEI LLSSAALAA & \multicolumn{2}{|c|}{ HFDIGETSVETVEIVLKMTT } & NYFNMLDLLVVAVSLISMGLESS & VKILRVLRVLRPLRAINRAKGL \\
\hline $\mathrm{Na}_{\mathrm{v}} 1.4 \mathrm{DIV}$ & TKQAFDITIMILICLNMVTMMV & \multicolumn{2}{|c|}{ NINMIFI I I FTGECVLKMLA } & VGWNIFDFVVVILSIVGLALSDL & FRVIRLARIGRVLRLIRGAKGI \\
\hline $\mathrm{Na}_{\mathrm{v}} 1.5 \mathrm{DIV}$ & TKQAFDVTIMFLICLNMVTMMV & \multicolumn{2}{|c|}{ KINLLFVAIFTGECIVKLAA } & NSWNIFDFVVVILSIVGTVLSDI & FRVIRLARIGRILRLIRGAKGI \\
\hline $\mathrm{Ca}_{\mathrm{v}} 1.1 \mathrm{DIV}$ & TSSYFEYLMFALIMLNTICLGM & \multicolumn{2}{|c|}{ ILNVAFTI I FTLEMI LKLMA } & DPWNVEDFLIVIGS I IDVILSEI & SAFFRLFRVMRLIKLLSRAEGV \\
\hline \multicolumn{3}{|c|}{$\begin{array}{l}\text { FIGURE } 2 \text { | Sequence alignment of the four TM segments of VSDs } \\
\text { from the VSD-featuring protein superfamily. The } \mathrm{Na}_{\mathrm{v}} 1.4, \mathrm{Na} \mathrm{v}_{\mathrm{v}} 1.5 \text {, } \\
\mathrm{C}_{\mathrm{v}} 1.1 \text {, and } \mathrm{K}_{\mathrm{v}} 7.1 \text { channels are shown. Members of the VSD-featuring } \\
\text { protein superfamily such as } H_{\mathrm{v}} 1 \text { and } C 15 \text { orf } 27 \text { are also shown. The } \\
S 1, \mathrm{~S} 2 \text {, and } S 3 \text { segments contain highly conserved negatively charged } \\
\text { and aromatic residues while the } S 4 \text { segment contains at least three }\end{array}$} & \multicolumn{3}{|c|}{$\begin{array}{l}\text { positively charged residues. Highly conserved residues are in bold } \\
\text { colors. Positively charged residues are in blue (arginine or lysine), } \\
\text { negatively charged residues are in red (aspartate or glutamate), and } \\
\text { aromatic residues are in green (phenylalanine or tyrosine). The } \\
\text { residues involved in the GCTC are annotated as F1, F2, E1, D1, and } \\
\text { R0 to R6. }\end{array}$} \\
\hline
\end{tabular}

amino acids (tryptophan, phenylalanine, or tyrosine) (Figure 2). Under the effect of voltage, the S4 segment moves toward the extracellular medium and causes a conformational change that results in the opening of the pore (Yang and Horn, 1995; Yang et al., 1996). The nature of this movement has been the subject of much debate. Three main models had been proposed: the sliding helix model (Catterall, 1986), the helical-screw model (Guy and Seetharamulu, 1986) and the paddle model (Jiang et al., 2003). Recent progress in modeling techniques has shown that the displacement of S4 is likely a blend of all three models (Delemotte et al., 2011). However, in order to clarify and better understand the nature of the movement of S4, studies have focused on the highly conserved residues shown in Figure 2. In 2004, Starace and Bezanilla substituted the first highly conserved arginine by a histidine on the $\mathrm{S} 4$ segment of the Shaker $\mathrm{K}^{+}$channel (R362H) (Starace and Bezanilla, 2004). This mutation was initially used to study the extracellular accessibility of the residue at rest. Interestingly, this study revealed that a proton $\left(\mathrm{H}^{+}\right)$leak current was created following the arginine-to-histidine substitution (Starace and Bezanilla, 2004). The authors concluded that the paddle model would have to be modified to reconcile the proposed structure and the experimental data. In a subsequent study, Tombola et al. showed that the neutralization of the first arginine on the S4 segment induced a cation leak through the VSD (R362A/C/H/S/V in the Shaker channel). The newly formed pore through which this leak occurred was called an omega pore (also known as a gating pore) to differentiate it from the physiological permeation pathway known as the alpha pore (Tombola et al., 2005).

\section{THE VOLTAGE SENSOR DOMAIN AND THE STRUCTURE OF GATING PORES}

Voltage sensitivity is important for a wide variety of physiological functions (Yu et al., 2005). Many voltage sensitive proteins
(VSPs) share a common structural motif called the VSD. VSDs are assemblies of four TM segments (S1-S4) (Figure 1). The S4 segment seems to be the central pillar of gating pores given that it drives conformational changes of VSDs. S4 is especially affected by voltage changes since it features several highly conserved positively charged amino acids (arginines or lysines) (Figure 2). Conserved residues on S1, S2, and S3 (Figure 2) appear to be involved either in the stabilization of S4 in different conformational states (Tao et al., 2010; Pless et al., 2011) or in the shape of the water crevices surrounding S4 (Pless et al., 2011). These water crevices are very important for focusing the electric field around the $\mathrm{S} 4$ segment. Alterations to the water crevices may change the movement kinetics of VSDs without necessarily changing the stability of their various states (Pless et al., 2011). There is also a complex of three highly conserved amino acids at the center of each VSD. This complex forms the gating charge transfer center (GCTC) (Figure 3) (Tao et al., 2010) and is composed of one aromatic residue (phenylalanine, tryptophan, or tyrosine) and two negatively charged residues (aspartic acid and glutamic acid) (Figure 3). The aromatic residue can interact with arginines through a cation- $\pi$ interaction (Pless et al., 2011), but it preferentially interacts with lysine to stabilize the activated or resting state of VSDs (Tao et al., 2010; Pless et al., 2011). The GCTC separates the intracellular and extracellular water crevices (Figure 3), which gives rise to a hydrophobic septum that also modulates the kinetics of the S4 segment. The larger the septum, the higher the free energy barrier is. As such, charged amino acids such as arginine and lysine need more energy to move through the septum. A large hydrophobic septum would delay the onset of the movement of S4 and changes its voltage sensitivity. Differences in the sizes of the hydrophobic septa of the domains of the $\mathrm{Na}_{\mathrm{v}} 1.4$ channel have been reported (Gosselin-Badaroudine et al., 2012a). Interestingly, the hydrophobic septum in domain IV is larger than the septa of the other domains. This is illustrated by comparing 


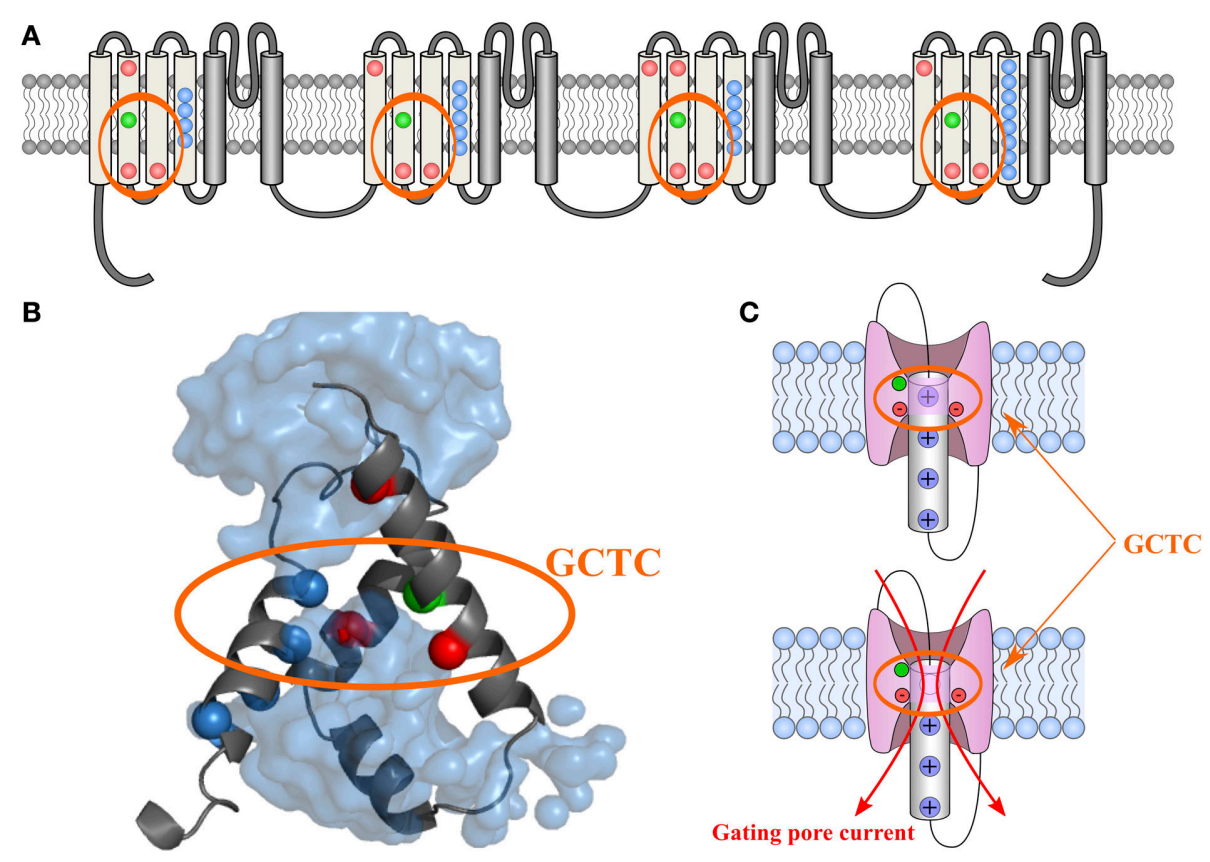

FIGURE 3 | 2-D and 3-D schematic representations of the GCTC. The 2-D structure of the Nav1.4 channel is shown in (A). The VSD motifs of the four domains are in light gray while the PD motifs are in dark gray. Highly conserved amino acids in the VSD motifs are in color. The blue, red, and green dots represent positively charged, negatively charged, and aromatic residues, respectively. The 3-D assembly of the $\mathrm{Na}_{v} 1.4$ DI VSD motif in its resting state, as published by Gosselin-Badaroudine et al. is shown in (B) (Gosselin-Badaroudine et al., 2012a). The model features the water crevices (light blue), the conserved arginine and lysine residues (dark blue), the conserved aspartate and glutamate residues (red), and the conserved tyrosine residue (green). As can be seen from the model, the first arginine residue is close to the GCTC. A schematic representation of the VSD motif in its resting state in the presence and absence of the first positively charged amino acid (the first arginine residue) is shown in (C). This representation highlights the fact that the neutralization of the amino acid in the R1 position would allow the water crevices to communicate when the VSDs are in the resting state and thus induce gating pore currents (Gosselin-Badaroudine et al., 2012a). the hydrophobic regions of domains I and IV (Figure 4). This larger septum in domain IV would explain the delayed activation of this VSD (Chanda and Bezanilla, 2002). A large septum would likely involve slower conformational changes to VSDs and be linked to more stable resting states.

Neutralizing the positively charged amino acid interacting with the GCTC at a given state creates a gating pore (Starace and Bezanilla, 2004; Tombola et al., 2005). If the charges of the GCTC are not counterbalanced by the charges of S4, the region becomes hydrophilic. The change from hydrophobic to hydrophilic implies that the water crevices are no longer separated, which allows ions to permeate through the newly formed narrow pore (Figure 3 ). Such pores have been used to probe the structures of the VSDs of various proteins (Starace and Bezanilla, 2004; Tombola et al., 2005; Gamal El-Din et al., 2010). They have also been used to explain features of VSDs in physiological conditions (Klassen et al., 2008; Berger and Isacoff, 2011; Musset et al., 2011) as well as pathological phenotypes (Sokolov et al., 2007; Struyk et al., 2008; Gosselin-Badaroudine et al., 2012b). However, caution is warranted when drawing conclusions based solely on the existence and modulation of a gating pore current. Specifically, it has been suggested that R362 (the first arginine residue on S4) interacts with E283 (the first highly conserved glutamate on S2) in the Shaker channel since an E283D mutation introduced into an $\mathrm{R} 362 \mathrm{C}$ background increases the gating pore current (Tombola et al., 2005). It appears that, in the wild type (WT) channel, R362 is closer to F290 (the first highly conserved phenylalanine on S2) (Figure 2) than E283. Residues located below this site preferentially form $\mathrm{Zn}^{2+}$ bridges with residues located above R362 (Lin et al., 2011). For instance, Lin et al. substituted a poorly conserved residue located below E283 (the I287 residue) with a histidine. In the background of this mutation, $\sim 56 \%$ of the channels that also featured a $\mathrm{R} 362 \mathrm{H}$ mutation could be momentarily trapped in their resting state when $\mathrm{Zn}^{2+}$ was present in the extracellular solution, indicating that $\mathrm{Zn}^{2+}$ can interact with both newly introduced histidine residues to form a $\mathrm{Zn}^{2+}$ bridge. However, in the background of the $\mathrm{I} 287 \mathrm{H}$ mutation, the $\mathrm{A} 359 \mathrm{H}$ substitution was more efficient at trapping the channels in their resting state since all the channels formed a $\mathrm{Zn}^{2+}$ bridge, indicating that I287 is closer to A359 than to R362, which would thus be located in close proximity to residues below I287. This is in agreement with reports that the positively charged residues of the S4 segment interact with the highly conserved aromatic amino acid in the S2 segment as observed in $K_{v}$ channels (Tao et al., 2010). However, this does not negate the fact that the R362C/E283D double mutant yields a larger gating pore than the R362C single mutant, which would indicate that mutant VSDs may feature stable conformational states slightly different from their WT counterparts. While we believe in the validity of the published reports, we advise caution. Indeed, to develop an artifact-free 


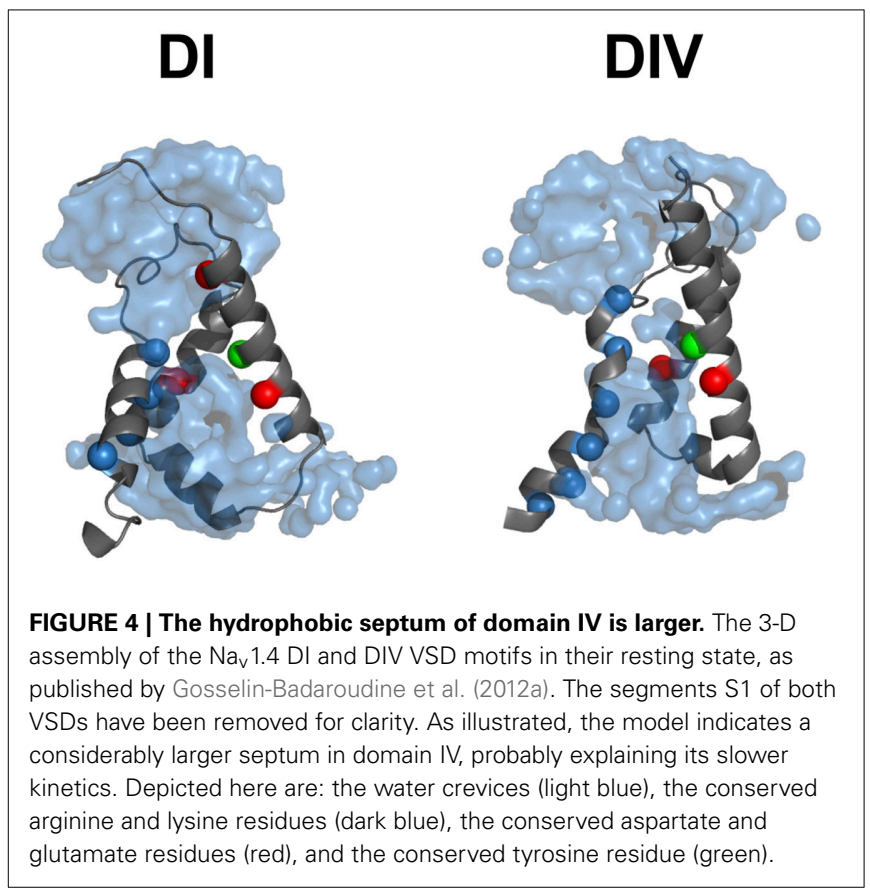

structural model of VSDs, interactions between highly conserved amino acids uncovered by the detection of gating pore currents should be confirmed using other techniques. For example, the creation of $\mathrm{Zn}^{2+}, \mathrm{Mg}^{2+}$, or cysteine bridges created using less critical, more poorly conserved residues located near the interaction of interest should confirm whether or not the more poorly conserved residues are in close proximity. It would be reasonable to conclude that the interactions of conserved residues also occur in WT channels if mutant channels featuring disruptive mutations (mutations yielding gating pore currents) and less disruptive mutations (mutations yielding bridges) point to the same conclusion.

\section{BIOPHYSICAL PROPERTIES OF GATING PORES GATING OF GATING PORES \\ Voltage-dependence}

Gating is paramount when describing ionic conductances. This property makes it possible to discriminate between ionic conductances. As mentioned previously, gating pores are open when the interaction between the S4 segment and the GCTC is abolished (Figures 3, 4), which means that gating pores can be created in both the resting state (Figure 5B) (Starace and Bezanilla, 2004; Tombola et al., 2005) and the activated state (Figure 5C) (Sokolov et al., 2008). In addition, few investigators have reported that mutations of the arginines interacting with the GCTC during the transition from the resting state to the activated state result in proton transport through VSDs, which is very similar to gating pore currents (Figure 5D) (Starace and Bezanilla, 2001, 2004).

Since the gating of gating pores is state-dependent, the probability of a gating pore being open at a given voltage is directly related to the probability of observing the VSD in the state of interest. A two-state Boltzmann distribution can be used to determine the probability of finding a VSD in a given state as a function of the membrane potential (Armstrong and Bezanilla, 1973). This allows the charge movement to be traced as a function of the voltage relationship (Q-V) (Figure 5A).

According to Boltzmann's law of distribution, the probability of observing a given particle (a VSD) in a given energy state is proportional to the following exponential (Equation 1):

$$
p \propto e^{-E / k T}
$$

where " $k$ " is Boltzmann's constant, " $T$ " is the temperature, and " $E$ " is the energy at which the particle is observed.

Since we assume a two-state system, the probability of observing the VSD in its activated state or in its resting state is 1 . Thus, the proportion of VSDs observed in a given state is represented by Equation (2):

$$
P_{1}=\frac{1}{1+e^{-\left(E_{1}-E_{2}\right) / k T}}
$$

Since the energy is normally applied as an electrical potential, the equation is usually written as:

$$
P_{\text {activated }}=\frac{1}{1+e^{z q_{e}\left(v_{1 / 2}-v_{m}\right) / k T}}
$$

where " $z$ " is the equivalent charge movement, " $q_{e}$ " is the elementary charge, " $V_{m}$ " is the electrical potential at which VSDs are observed, and " $V_{1 / 2}$ " is the electrical potential at which half the VSDs are in their activated state.

Such a statistical distribution implies that the VSDs transition to the activated state as a function of voltage, expressed by the following equation:

$$
\frac{d P_{\text {activated }}}{d V}=\frac{z q_{e} e^{\left(v_{1 / 2}-v_{m}\right) / k T}}{k T\left(e^{z q_{e}\left(v_{1 / 2}-v_{m}\right) / k T}+1\right)^{2}}
$$

This indicates that not all VSDs change states at the same voltage. Moreover, the area under the energy distribution curve from 0 to a given voltage represents the proportion of VSDs that have a sufficient amount of energy to be observed in their activated state at the given voltage (Figure 5A).

The Q-V curve directly fits the Boltzmann equation of a two-state system mentioned earlier. The opening probability of the gating pore is given by the Q-V curve for VSDs for which the S4-GCTC interaction is suppressed in the activated state (Equation 3). In the case of an S4-GCTC interaction suppressed in the resting state, the opening probability is given by 1 minus the $\mathrm{Q}-\mathrm{V}$ curve. This means that the gating pore can either be defined as an inward rectifying conductance if the S4-GCTC interaction is suppressed in the resting state or as an outward rectifying conductance if the S4-GCTC interaction is suppressed in the activated state (Figure 5).

$\mathrm{H}^{+}$transport due to the suppression of the S4-GCTC interaction in transition states is a special case as this $\mathrm{H}^{+}$transport is maximal when the transition rate of the VSD is maximal (Figure 5D). The transition rates are maximal at the $\mathrm{V}_{1 / 2}$ of the $\mathrm{Q}-\mathrm{V}$ curve, which is also the voltage value at which the number 


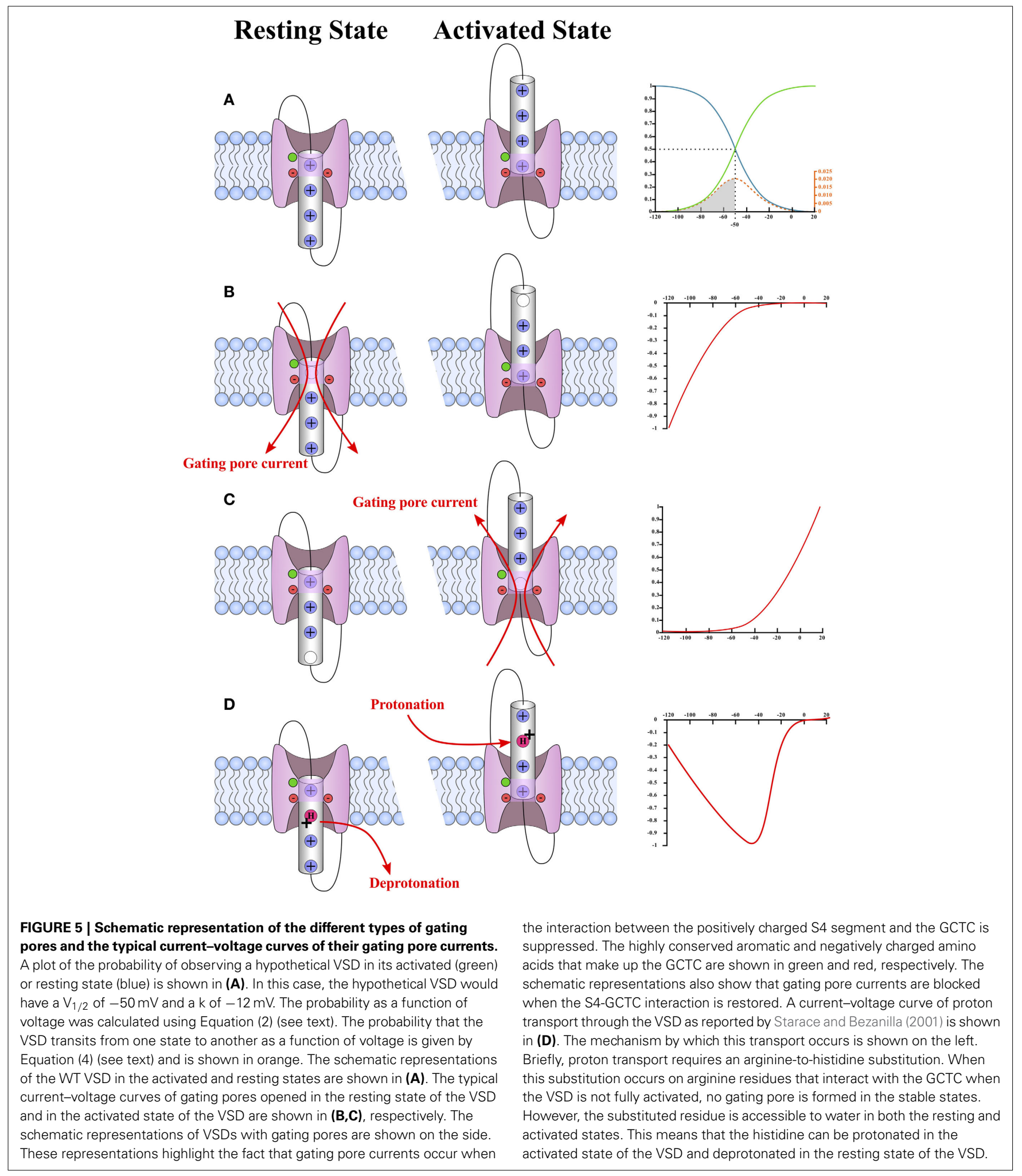

of VSDs changing states is the highest (as seen by the energy distribution curve) (Figure 5). Such $\mathrm{H}^{+}$transport has already been observed with Shaker $\mathrm{K}^{+}$channels (Starace and Bezanilla, 2004).

\section{Kinetics}

The activation kinetics of gating pores are very rapid, with its onset being less than $1 \mathrm{~ms}$. Once activated, gating pores do not inactivate since VSDs tend to stay in their 
activated state until the TM voltage returns to hyperpolarizing values.

Due to their nature, the biophysical characteristics of gating pores are intimately linked to the state, environment, and movement of the S4 segment. This provides several advantages, notably for structure-function studies. As such, the voltage-dependence of gating pore currents can be used as a read-out of the movement of individual voltage sensors (Gosselin-Badaroudine et al., 2012a).

\section{SELECTIVITY AND CONDUCTANCE OF GATING PORES Selectivity}

Few studies have investigated the selectivity of gating pores (Table 1) (Tombola et al., 2005; Sokolov et al., 2007; Klassen et al., 2008; Berger and Isacoff, 2011; Francis et al., 2011). The selectivity sequences reported by Tombola et al., Sokolov et al., and Francis et al. indicate that gating pores may typically be more permeable to large cations than small cations (Tombola et al., 2005; Sokolov et al., 2007; Francis et al., 2011). The selectivity sequences thus seem to converge toward Eisenmann's first or second sequence, which corresponds to the selectivity sequences of narrow pores with weak binding sites (Eisenman, 1962). Such pores rely heavily on ion dehydration to limit permeation to large ions (Figure 6). Small ions, which have a high charge density, need more energy to dehydrate. This gives them a larger effective radius, which decreases their relative permeability (Figure 6).

$\mathrm{NMDG}^{+}$(N-Methyl-D-Glucamine) and $\mathrm{TEA}^{+}$(Tetra-Ethyl Ammonium), two cations that are larger than $\mathrm{K}^{+}$, have been reported to flow through gating pores (Sokolov et al., 2007; Francis et al., 2011). Interestingly, the conductance values for $\mathrm{NMDG}^{+}$and $\mathrm{TEA}^{+}$are lower than for $\mathrm{K}^{+}$. This seems to contradict the hypothesis that gating pores typically follow Eisenmann's first two selectivity sequences. Once dehydrated, $\mathrm{NMDG}^{+}$and $\mathrm{TEA}^{+}$would either be small enough or too big to flow through this permeation pathway. In this case, gating pores would be less permeable to $\mathrm{K}^{+}$than to $\mathrm{NMDG}^{+}$or $\mathrm{TEA}^{+}$since their charge density is lower (Figure 6). However, the studies reporting that $\mathrm{NMDG}^{+}$and $\mathrm{TEA}^{+}$flow through gating pores were both performed with extracellular solutions adjusted to $\mathrm{pH}$ 7.4. It is thus possible that the currents were the result of the permeation of $\mathrm{H}^{+}$ rather than $\mathrm{NMDG}^{+}$or $\mathrm{TEA}^{+}$.

It has been reported that some mutations involving histidine substitutions in the Shaker, $\mathrm{Na}_{\mathrm{v}} 1.4$, and $\mathrm{Na}_{\mathrm{v}} 1.5$ channels yield gating pores that are selective to $\mathrm{H}^{+}$alone (Starace and Bezanilla, 2004; Campos et al., 2007; Struyk and Cannon, 2007; GosselinBadaroudine et al., 2012a,b). It is noteworthy that the permeation of $\mathrm{H}^{+}$through VSDs is postulated to occur via a Grotthus hopping mechanism via water wires on each side of the membrane (Starace and Bezanilla, 2004).

Indirect evidence for the flow of anions through mutant $\mathrm{H}_{\mathrm{V}} 1$ channels has recently been reported (Musset et al., 2011). It would thus be interesting to investigate this type of permeation in other VSDs.

\section{Conductance of gating pores}

Several data sets describe the conductance of gating pores (Table 2) (Cherny et al., 2003; Starace and Bezanilla, 2004;

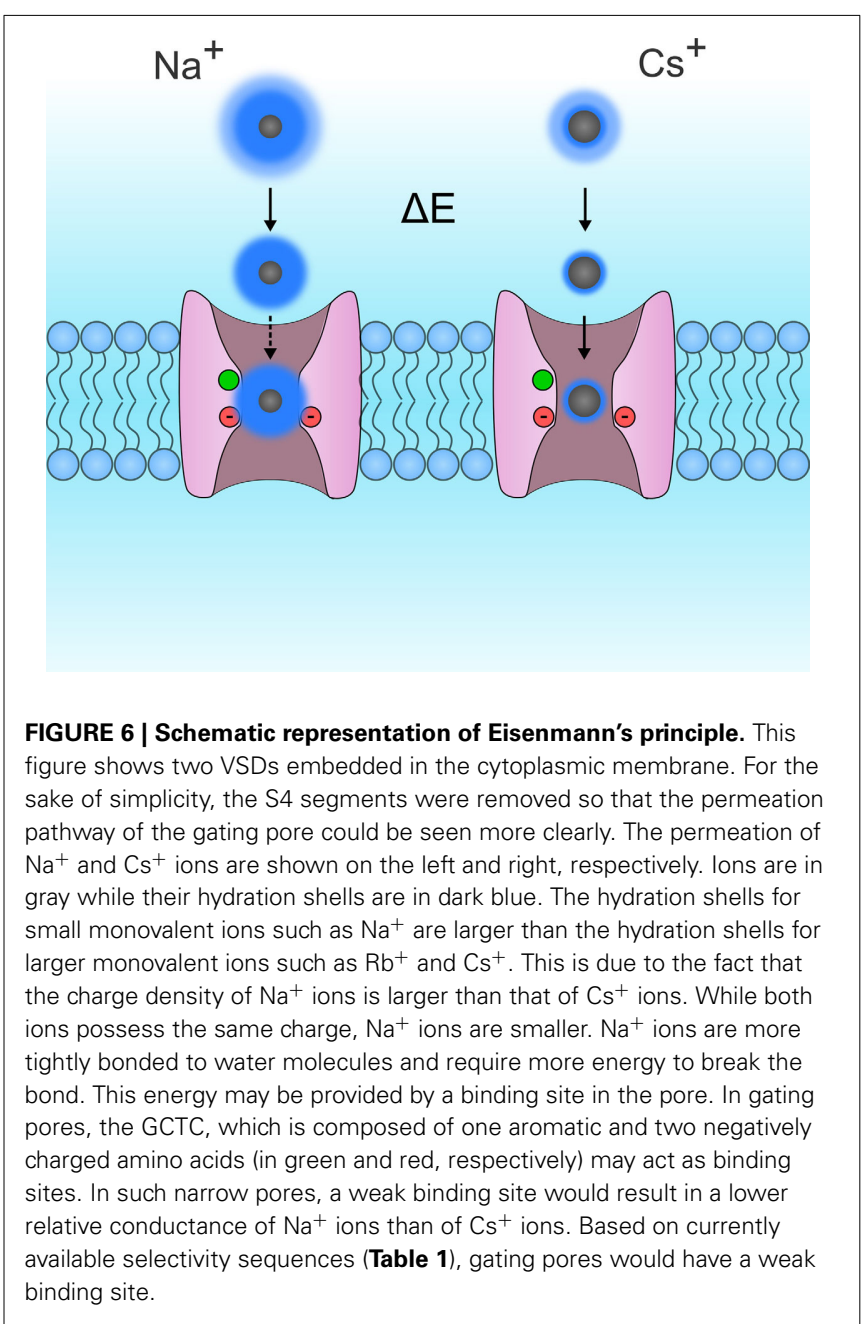

Table 1 | Selectivity sequences of various gating pores.

\begin{tabular}{|c|c|c|c|c|}
\hline Channel & Mutation & Location & Selectivity & References \\
\hline dShaker & R362C & $\mathrm{R} 1$ & Guanidium $>\mathrm{Cs}>\mathrm{K}>\mathrm{Li}$ & Tombola et al., 2005 \\
\hline $\mathrm{rNa}_{\mathrm{v}} 1.4$ & R666G & DII/R2 & $\mathrm{Cs} \sim \mathrm{K}>\mathrm{Na} \sim \mathrm{Li}>\mathrm{TEA} \sim \mathrm{NMDG}$ & Sokolov et al., 2007 \\
\hline N.at-K 3.2 & None* & None* & $\mathrm{K}>\mathrm{Cs} \sim$ Guanidium $>\mathrm{Na} \sim \mathrm{Ba}$ & Klassen et al., 2008 \\
\hline $\mathrm{hH}_{\mathrm{v}} 1$ & R211S & R3 & Guanidium $>\mathrm{Li}>\mathrm{H}>\mathrm{Cs} \sim \mathrm{K} \sim \mathrm{Na}$ & Berger and Isacoff, 2011 \\
\hline$r \mathrm{Na}_{\mathrm{v}} 1.4$ & R11250 & DIII/R2 & $\mathrm{K}>\mathrm{Na}>>\mathrm{NMDG}$ & Francis et al., 2011 \\
\hline
\end{tabular}

${ }^{*}$ For the gating pore of $N . a t-K_{\mathrm{v}} 3.2$, no substitution was required to induce a gating pore. 
Table 2 | Conductance values reported for various gating pores.

\begin{tabular}{|c|c|c|c|c|c|c|}
\hline Channel & Mutation & Location & Conductance & $\begin{array}{l}\text { Ion used for } \\
\text { measurement }\end{array}$ & Evaluation mode & References \\
\hline dShaker & $\mathrm{R} 362 \mathrm{H}$ & $\mathrm{R} 1$ & $40 \mathrm{fS}$ & $\mathrm{H}^{+}$ & Fluctuation analysis & $\begin{array}{l}\text { Starace and Bezanilla, } \\
2004\end{array}$ \\
\hline dShaker & R362C and R362C/E283D & $\mathrm{R} 1$ and S2/E1 & $100-600 \mathrm{fS}$ & $\mathrm{K}^{+}$ & $\mid \omega / / \alpha$ & Tombola et al., 2005 \\
\hline dShaker & A359G/R362S & $\mathrm{R} 0$ and $\mathrm{R} 1$ & $1410 \mathrm{fS}$ & $\mathrm{K}^{+}$ & Fluctuation analysis & Tombola et al., 2007 \\
\hline dShaker & R362S/E283D/S357C/M356D & $\mathrm{R} 1, \mathrm{~S} 2 / \mathrm{E} 1$ and others & $3420 \mathrm{fS}$ & $\mathrm{K}^{+}$ & Fluctuation analysis & Tombola et al., 2007 \\
\hline $\mathrm{rNa}_{\mathrm{v}} 1.4$ & $\mathrm{R} 663 \mathrm{H}$ & DII/R1 & $0,17 \mathrm{fS}$ & $\mathrm{H}^{+}$ & $\mathrm{I}_{\omega} / \mathrm{Q}_{\mathrm{on}}$ & Struyk and Cannon, 2007 \\
\hline $\mathrm{rNa}_{\mathrm{v}} 1.4$ & $\mathrm{R} 666 \mathrm{H}$ and $\mathrm{R} 666 \mathrm{G}$ & DII/R2 & $34 \mathrm{fS}$ & $\begin{array}{l}\text { not clear }\left(\mathrm{H}^{+}\right. \\
\left.\text {and/or } \mathrm{Na}^{+}\right)\end{array}$ & $\mathrm{I}_{\omega} / \mathrm{Q}_{\mathrm{on}}$ & Struyk et al., 2008 \\
\hline $\mathrm{rNa}_{\mathrm{v}} 1.4$ & R6690, R669G and R669W & DII/R3 & $1060 \mathrm{fS}$ & $\mathrm{Na}^{+}$ & $\mathrm{I}_{\omega} / \mathrm{l}_{\alpha}$ & Sokolov et al., 2008 \\
\hline $\mathrm{rNa}_{\mathrm{v}} 1.4$ & R666G & DII/R2 & $530 \mathrm{fS}$ & $\mathrm{Na}^{+}$ & $\mathrm{I}_{\omega} / \mathrm{l}_{\alpha}$ & Sokolov et al., 2010 \\
\hline $\mathrm{rNa}_{\mathrm{v}} 1.4$ & R11250 & DIII/R2 & $34 \mathrm{fS}$ & $\mathrm{Na}^{+}$ & $\mathrm{I}_{\omega} / \mathrm{Q}_{\mathrm{on}}$ & Francis et al., 2011 \\
\hline $\mathrm{hH}_{\mathrm{v}} 1$ & None* & & $38-400 \mathrm{fS}$ & $\mathrm{H}^{+}$ & Fluctuation analysis & Cherny et al., 2003 \\
\hline
\end{tabular}

Evaluation modes:

Fluctuation analysis: Analysis of the variance of the current as per Sigworth (1980).

$I_{\omega} / Q_{o n}$ : Normalization of the gating pore current to the observed gating charge.

$I_{\omega} / l_{\alpha}$ : Normalization of the gating pore current to the maximum current of the alpha pore.

* For $h H_{v} 1$, the neutral residue in the R4 position appears to be involved in the creation of a conduction pathway through the VSD.

Sokolov et al., 2007, 2008, 2010; Struyk and Cannon, 2007; Tombola et al., 2007; Struyk et al., 2008; Francis et al., 2011; Gosselin-Badaroudine et al., 2012a,b). Given the diversity of the gating pores investigated and the methods used to carry out the investigations, no consensus seems to have emerged concerning the conductance of gating pores. To compare the conductance values obtained from different studies, we converted all the values into Siemens (Table 2). In these cases, some assumptions had to be made. At voltages of $-140 \mathrm{mV}$ and lower, the assumption was that the open probability for gating pores at hyperpolarizing voltages is 1 . Given that, at this voltage, the current follows Ohm's law, the conductance should be maximal, and the driving force should be the only parameter impacting the value of the current value. Nevertheless, there is evidence that the open probability for gating pores might not be 1 in such cases (Tombola et al., 2007). Assuming unitary conductances of $25 \mathrm{pS}$ and $22 \mathrm{pS}$ for the alpha pores of the $\mathrm{Na}_{\mathrm{v}} 1.4$ and $\mathrm{Na}_{\mathrm{v}} 1.5$ channels, respectively (Gellens et al., 1992; Chahine et al., 1994a), we calculated the corresponding conductance values based on the gating pore currents measured, the voltages at which they were measured, and the solutions used (Table 2 ). The values measured and calculated span a wide range (0.17-1060 fS for gating pores created with single mutations and up to $3400 \mathrm{fS}$ for gating pores created with multiple mutations) (Table 2). Interestingly, major discrepancies have been reported in the values of gating pore conductances of the $\mathrm{Na}_{\mathrm{v}} 1.4 / \mathrm{R} 666 \mathrm{G}$ mutant channel using similar techniques (Sokolov et al., 2007, 2008, 2010; Struyk and Cannon, 2007; Struyk et al., 2008). The discrepancies may be mostly due to the different mutations and the wide variety of proteins (Table 2 ).
The conductance of pores created by arginine-to-histidine mutations should be treated as special cases since their permeation mechanism is different. Arginine-to-histidine mutations yield gating pore currents that are highly selective for $\mathrm{H}^{+}$. The conductance of these pores would be primarily modulated by the accessibility of the histidine residue to the GCTC. When the histidine residue is very close to the GCTC and the water crevices are deep, the pores would display high conductances.

\section{NATURALLY OCCURRING GATING PORES GATING PORE CURRENTS IN PHYSIOLOGICAL CONDITIONS}

When observed in living organisms, gating pore currents are mainly described as a pathogenic process associated with naturally occurring mutations. Nevertheless, they can be found in few physiological conditions. The $\mathrm{H}_{\mathrm{V}} 1$ channel (also called HVCN1 or VSOP) is structurally composed of four TM segments with cytoplasmic C- and N-termini (Capasso et al., 2011) (Figure 1). Interestingly, this protein does not feature the S5-S6 motif frequently associated with selective ion conduction (Figure 1). However, this channel is similar to the VSDs of other VGICs (Figures 1, 2) (Ramsey et al., 2006; Sasaki et al., 2006). It has been reported that $\mathrm{H}^{+}$ions can permeate the protein via the VSD using a proton-wire mechanism (Nagle and Morowitz, 1978; Decoursey, 2013). According to the definition of gating pore currents put forward by Tombola et al. (2005), $\mathrm{H}_{\mathrm{V}} 1$ currents can be considered as gating pore currents. Physiologically, the activation of this channel causes an efflux of cytoplasmic $\mathrm{H}^{+}$(Decoursey, 2003). 
$\mathrm{H}_{\mathrm{v}} 1$ plays key roles in numerous processes such as phagocytosis, spermatozoa maturation, and $\mathrm{B}$ cell activation (Capasso et al., 2011). The activation of $H_{v} 1$ results in the regulation of NADPH (Nicotinamide Adenine Dinucleotide Phosphate) function, ensuring an optimal $\mathrm{pH}$ in phagocytosis vesicles (Decoursey, 2003). The $H_{v} 1$ channel is also involved in cardiac function (El Chemaly et al., 2006). The involvement of gating pore currents mediated by $\mathrm{H}_{\mathrm{v}} 1$ in a wide array of functions highlights its physiological importance.

Naturally occurring gating pore currents in platyhelminthes (flat worms) are another example of the involvement of gating pores in physiological functions. $\mathrm{A} \mathrm{K}^{+}$channel expressed in flat worms (N.at $\left.-K_{\mathrm{v}} 3.2\right)$ naturally conducts ions through the VSD (Klassen et al., 2008). These channels display unusual properties compared to other $K_{v}$ channels of the Shaw family $\left(\mathrm{K}_{\mathrm{v}} 3\right.$ family) (Klassen et al., 2006). Surprisingly, WT N.at-K 3.2 channels exhibit inward-rectifier currents that are activated by hyperpolarization. The N.at $-K_{\mathrm{v}} 3.2$ protein structure is composed of six TM. Its pore region is very similar to that of other $K_{v}$ channels. However, the S4 helix features two atypical residues (a histidine and a glycine) in positions where the first and third arginines are usually found (Figure 2) (Klassen et al., 2008). This enables the permeation of cations through the VSDs of N.at- $K_{\mathrm{V}} 3.2$ channels due to the lack of positively charged residues on S4 (Figure 2). Hyperpolarization-activated currents in these channels are gating pore currents. In this flat worm, gating pore currents would be involved in their physiological functions. Unfortunately, their exact physiological role is unknown.

\section{ARE GATING PORES A FEATURE OF EVOLUTION?}

Klassen et al. proposed that gating pores in N.at- $K_{\mathrm{v}} 3.2$ have evolved to produce a non-selective cation channel resulting in the creation of a new molecular property (Klassen et al., 2008) adapted for a specific physiological need. From an evolutionary point of view, VGICs could be the result of the evolution of a unique TM segment (an S3-like segment) (Kumanovics et al., 2002) that is responsible for sensing membrane curvature. This unique TM could then have evolved into a VSD, which would have become fine-tuned for voltage sensing before coupling with pre-existing pores. This assembly would form the VGIC (Kumanovics et al., 2002). Such an assembly is in agreement with the discovery of other channels such as $H_{v} 1$, which are only composed of a VSD (Ramsey et al., 2006; Capasso et al., 2011) and voltage-dependent phosphatases such as Ciona intestinalis voltage-sensitive phosphatase (Ci-VSP) (Murata et al., 2005). These phosphatases are examples of a different evolutionary pathway of the VSD motif. Indeed, depending on the subtype of protein assembly, different physiological functions can appear. In this case, Ci-VSP is directly coupled to and activated by a VSD (Murata et al., 2005). Later in the evolutionary process, four subunits composed of a VSD and a pore domain fused to form $\mathrm{Na}_{\mathrm{V}}$ and $\mathrm{Ca}_{\mathrm{v}}$ channels (Kumanovics et al., 2002). Even if the naturally occurring gating pores in $N . a t-K_{\mathrm{v}} 3.2$ can be considered as evolutionary precursors of VSDs, they are (together with $\mathrm{H}_{\mathrm{v}} 1$ ) the only known naturally occurring gating pores. Most known gating pores are in vitro creations, or are of pathological origin, which would likely exert negative selection pressure and decrease the probability of conserving these gating pores throughout the evolutionary process.

\section{PATHOLOGIES LINKED TO GATING PORE CURRENTS PERIODIC PARALYSIS Hypokalemic periodic paralysis}

Hypokalemic periodic paralysis (HypoPP) is a rare autosomal dominant disorder characterized by recurrent attacks of paralysis in the presence of low serum $\mathrm{K}^{+}(<3 \mathrm{mEq} / \mathrm{L})$. Paralysis episodes can be triggered by carbohydrate-rich meals, exercise, exposure to cold, fever, or emotional stress (Cannon, 2006; Sung et al., 2012). The current explanation for these paralysis attacks is that the resting membrane potential $\left(\mathrm{V}_{\mathrm{REST}}\right)$ changes from $-85 \mathrm{mV}$ to $-60 \mathrm{mV}$ under hypokalemic conditions, leading to muscle fiber inexcitability (Rudel et al., 1984; Jurkat-Rott et al., 2009). To date, 16 mutations on the CACNA1S and SCN4A genes have been shown to cause HypoPP-1 and HypoPP-2, respectively (Figure 7). These two genes encode $\mathrm{Ca}_{\mathrm{v}} 1.1$ and $\mathrm{Na}_{\mathrm{v}} 1.4$, respectively. Missense mutations have been found on their S4 segments (six for CACNA1S and ten for SCN4A, Figures 2, 6) (JurkatRott et al., 2012; Groome et al., 2014). Mutations on CACNA1S account for approximately $60 \%$ of HypoPP cases while mutations on SCN4A account for 10\% (Tricarico and Camerino, 2011). Initial studies have revealed that missense mutations cause some discrete changes in currents carried by the mutated channels (Lapie et al., 1996; Morrill et al., 1998; Jurkat-Rott et al., 2000). Interestingly, mutations causing HypoPP are reported to result in a number of changes to the biophysical properties of the channels. For example, some HypoPP mutations on $\mathrm{Ca}_{\mathrm{v}} 1.1$ may solely affect current density while others may result in slower channel activation (Lapie et al., 1996; Morrill et al., 1998). On the other hand, HypoPP mutations on $\mathrm{Na}_{\mathrm{v}} 1.4$ are reported to lead to divergent biophysical defects since they result in enhanced or reduced channel inactivation (Jurkat-Rott et al., 2000). Nevertheless, these changes cannot fully explain the depolarization observed during paralysis episodes (Cannon, 2010). The specific location of the mutations on the S4 segments (Figure 7) of the two genes led the researchers to focus on finding a common pathologic mechanism. Gating pore currents were described as the common mechanism leading to the muscular pathology (Sokolov et al., 2007; Struyk and Cannon, 2007). At this juncture, two types of mutations have been described: mutations leading to the creation of a cationic leak (Sokolov et al., 2007) and mutations leading to the creation of an $\mathrm{H}^{+}$-specific leak (arginine-to-histidine substitutions) (Struyk and Cannon, 2007).

Several processes have been proposed to explain this pathology. Primarily, the elevation of $\mathrm{V}_{\mathrm{REST}}$ induces the inactivation of $\mathrm{Na}_{\mathrm{v}} 1.4$ thus abrogating the ability to excite muscle fibers. The $\mathrm{V}_{\text {REST }}$ of a muscular fiber is mainly set by $\mathrm{K}_{\mathrm{ir}}$ (Inward Rectifier Potassium Channels) (Hibino et al., 2010; Wu et al., 2011). In severe hypokalemia $(<1 \mathrm{mM}), \mathrm{K}_{\mathrm{ir}}$ activity is reduced. In HypoPP, the inward $\mathrm{Na}^{+}$or $\mathrm{H}^{+}$leak induced by mutations of $\mathrm{Na}_{\mathrm{v}} 1.4$ or $\mathrm{Ca}_{\mathrm{v}} 1.1$ inhibits $\mathrm{K}_{\text {ir }}$ currents under relatively low kalemia conditions $\left(2.5-3 \mathrm{mM} \mathrm{K}^{+}\right.$) (Figure 8). The reduction in the outward $\mathrm{K}^{+}$current then causes an elevation in $\mathrm{V}_{\text {REST }}$ (Struyk et al., 2008; Jurkat-Rott et al., 2009; Cannon, 2010; Tricarico and Camerino, 2011; Wu et al., 2011). Gating pore currents also induce a $\mathrm{Na}^{+}$ 


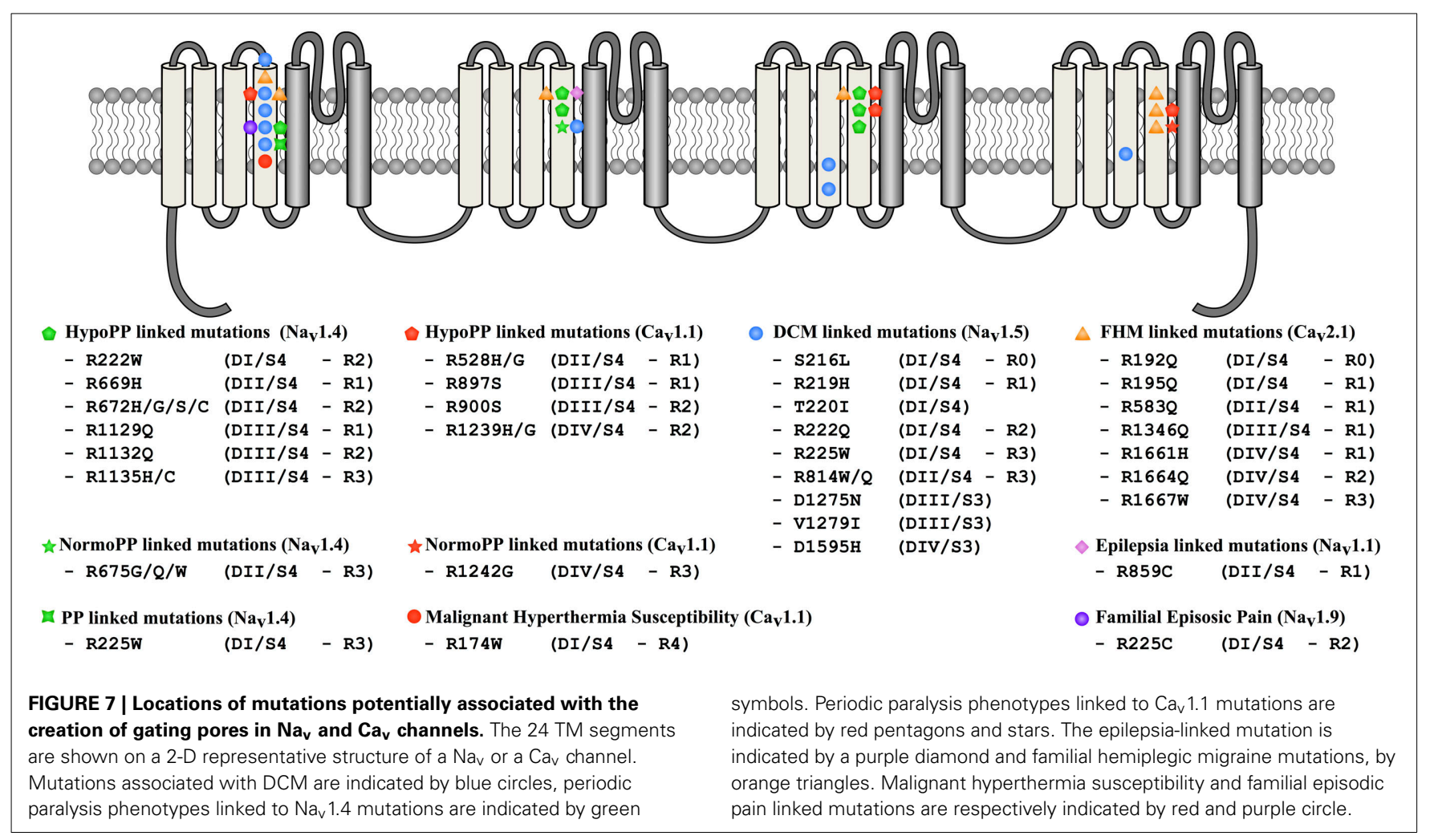

overload in muscle fibers, which has already been reported by Jurkat-Rott et al. (Jurkat-Rott et al., 2009). The $\mathrm{Na}^{+}$overload further destabilizes ionic homeostasis (Figure 8). Several membrane exchangers can also be activated, including $\mathrm{Na}^{+} / \mathrm{K}^{+}$ATPase, $\mathrm{Na}^{+} / \mathrm{H}^{+}, \mathrm{Na}^{+} / \mathrm{Ca}^{2+}, \mathrm{Na}^{+} / \mathrm{Lac}^{-}$, and $\mathrm{Na}^{+} /$bicarbonate. $\mathrm{Na}^{+} / \mathrm{H}^{+}$ exchangers usually extrude $\mathrm{H}^{+}$from the cell to regulate the internal $\mathrm{pH}$. However, this exchanger may work in reverse mode (Hilgemann et al., 2006), which would result in intracellular acidosis. In addition, the exact downstream events resulting from a $\mathrm{Na}^{+}$overload are not fully understood. Nevertheless, detrimental consequences have been described (Pieske et al., 2003; Maack et al., 2006; Kohlhaas et al., 2010). A Na ${ }^{+}$overload may also increase the mitochondrial production of reactive oxygen species (Kohlhaas et al., 2010), which would result in an increase in oxidative stress, leading to cellular remodeling as well as excitationcontraction uncoupling, and electrical disturbances (Pieske et al., 2003; Maack et al., 2006; Kohlhaas et al., 2010).

Mutations that induce $\mathrm{H}^{+}$-selective gating pores are linked to the same phenotype as mutations that induce cation-selective gating pores (Struyk et al., 2008) (Figure 8), indicating that they have similar downstream consequences although through slightly different mechanisms. This could be explained by the activity of the exchangers described previously. $\mathrm{H}^{+}$leaks and intracellular acidification can have specific impacts on muscular fibers, including the blockade of $\mathrm{K}_{i r}$ (Figure 8) (Tricarico and Camerino, 2011), which would increase the depolarization process. Acidification can also lead to connexin uncoupling (Bukauskas et al., 2001) and the impairment of excitation-contraction coupling by decreasing the affinity of troponin $\mathrm{C}$ for $\mathrm{Ca}^{2+}$ (Figure 8) (Fabiato and
Fabiato, 1978; Ball et al., 1994; Palmer and Kentish, 1994; Parsons et al., 1997). HypoPP muscle fibers display certain peculiarities such as the formation of vacuoles (vacuolar myopathy) and tubular aggregates (Sternberg et al., 2001; Jurkat-Rott et al., 2009; Tricarico and Camerino, 2011; Wu et al., 2011). Wu et al. also reported that sarcoplasmic triads are dilated in their HypoPP knock-in mouse model (Wu et al., 2011, 2012). All these morphological changes, while they have not been studied in depth, attest to the diverse impacts of gating pore currents $\left(\mathrm{H}^{+}\right.$-specific or not). Unfortunately, the processes leading to morphological changes are unknown.

Wu et al. recently described the link between HypoPP-1 and mutations on $\mathrm{Ca}_{\mathrm{v}} 1.1$. They used a knock-in mouse model and reported that gating pore currents are induced in $\mathrm{Ca}_{\mathrm{v}} 1.1$ channels featuring an arginine-to-histidine mutation in the S4 segment (Wu et al., 2012). Their study confirmed that the pathogenic process leading to HypoPP-1 may be similar to the process described for HypoPP-2.

\section{$\mathrm{K}^{+}$-sensitive normokalemic periodic paralysis}

At physiological $\mathrm{K}^{+}$concentrations, some patients express a variant of HypoPP called $\mathrm{K}^{+}$-sensitive normokalemic periodic paralysis (NormoPP). Vicart et al. identified three new mutations of the third arginine of the S4 segment of DII of the human $\mathrm{Na}_{\mathrm{v}} 1.4$ protein (R675G/Q/W) (Figure 7) (Vicart et al., 2004). A biophysical study of these mutants showed that gating pore currents appeared under depolarized conditions while the usual biophysical properties were only slightly impacted (Sokolov et al., 2008). The main characteristic of these gating pore currents is an ionic 


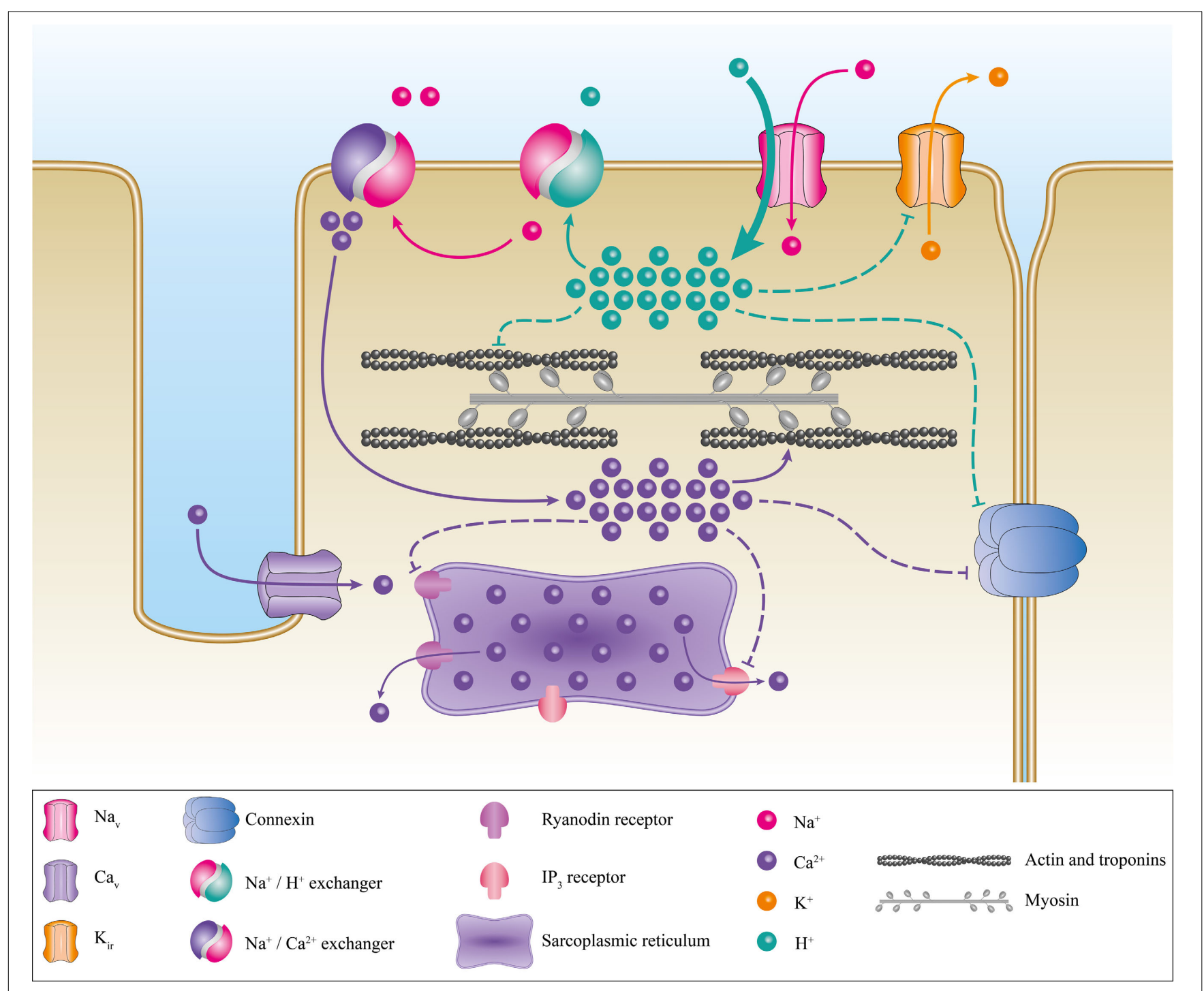

FIGURE 8 | Proposed pathogenic mechanism associated with the creation of a gating pore. Schematic representation of a myocyte with its main ionic channels and exchangers. The contractile proteins, the sarcoplasmic reticulum, and connexins are in gray, purple, and blue, respectively. The appearance of a gating pore current induces a disequilibrium of ionic homeostasis through the activation of several exchangers such as $\mathrm{Na}^{+} / \mathrm{H}^{+}$and $\mathrm{Na}^{+} / \mathrm{Ca}^{2+}$. This would result in a $\mathrm{Ca}^{2+}$ overload. The disequilibrium then destabilizes the resting membrane potential, connexin activity, and excitation-contraction coupling. The pathogenic mechanism resulting in the creation of a cation-selective gating pore current is not shown here. However, it would be similar to the pathogenic mechanism resulting in a proton-selective gating pore current. A cation-selective gating pore current would inhibit $K_{\text {ir }}$ channels, thus increasing the resting membrane potential. A gating pore current would inhibit the $\mathrm{Na}^{+} / \mathrm{H}^{+}$exchanger and activate the $\mathrm{Na}^{+} / \mathrm{Ca}^{2+}$ exchanger. This would result in acidosis and a $\mathrm{Ca}^{2+}$ overload. leak when $\mathrm{Na}_{\mathrm{v}} 1.4$ is in the activated state (mostly $\mathrm{K}^{+}$efflux) and slow-inactivated state (mostly $\mathrm{Na}^{+}$influx) (Sokolov et al., 2008). The $\mathrm{Na}^{+}$influx during the slow-inactivated state occurs when the membrane potential is hyperpolarized. The mutations may stabilize the S4 segment in the activated state (Sokolov et al., 2008). Vicart et al. attributed the pathological mechanism to the large increase in the $\mathrm{Na}^{+}$influx in the slow-inactivated state. Recently, the R1242G mutation on $\mathrm{Ca}_{\mathrm{v}} 1.1$ channels has also been associated with the development of NormoPP (Fan et al., 2013). Gating pore currents have been recorded in the depolarized state, suggesting a common pathological mechanism. The study also confirmed that an inward gating pore current can be recorded under hyperpolarized voltages after a long depolarization period (Fan et al., 2013). Interestingly, the $\mathrm{R} 1135 \mathrm{H} / \mathrm{C}$ mutations have recently been associated to the development of HypoPP phenotype (Groome et al., 2014). These mutations also induce gating pore activated by depolarization. Furthermore, the study reveals the presence of gating pore current under hyperpolarized conditions probably associated with the freezing of the VSD after long depolarizations.

Intriguingly, Lee et al. described a patient affected by myotonia that was triggered by cold exposure and that was associated with transient weakness (Lee et al., 2009). The genetic study revealed 
the presence of a SCN4A mutation that changed the third $\mathrm{R}$ of DI of the S4 segment to a W (R225W) (Figures 2, 6). While the clinical phenotype was not classified as HypoPP or NormoPP, the mutation was strongly associated with the development of muscular weakness. The creation of a gating pore, which is activated by depolarization due to the mutation, is highly probable (Figure 5C) and may be the cause of the pathology.

\section{MIXED ARRHYTHMIAS ASSOCIATED WITH DILATED CARDIOMYOPATHY}

DCM is the most common cardiac disorder. It is characterized by left ventricular dilatation $(>117 \%)$ and systolic dysfunction (ejection fraction inferior to 45\%) (Richardson et al., 1996; Taylor et al., 2006; McNair et al., 2011). DCM has a prevalence of 1 in 2500 and an annual incidence of 7 in 100,000 a year (Taylor et al., 2006). Some $20-48 \%$ of DCM cases are classified as familial DCM (Hershberger and Siegfried, 2011). To date, 33 genes, most of which code for cytoskeleton or contractile proteins, have been associated with familial DCM (Hershberger and Siegfried, 2011). McNair et al. recently reported that SCN5A is linked to $1.7 \%$ of familial DCM cases (McNair et al., 2011). The SCN5A gene codes for the cardiac $\mathrm{Na}_{\mathrm{v}} 1.5$ channel, which is responsible for the initiation of the action potential in the heart. Its role is comparable to that of $\mathrm{Na}_{\mathrm{v}} 1.4$ in skeletal muscles. So far, 18 SCN5A mutations have been associated with the development of severe arrhythmias and heart dilatation. Ten of the mutations are located on the VSD (S216L, R219H, T220I, R222Q, R225W, R814W, R814Q, D1275N, V1279I, and D1595H) (Figure 7) (Bezzina et al., 2003; McNair et al., 2004; Frigo et al., 2007; Ge et al., 2008; Hershberger et al., 2008; Hedley et al., 2009; McNair et al., 2011; GosselinBadaroudine et al., 2012b; Laurent et al., 2012). While $\mathrm{Na}_{\mathrm{v}} 1.5$ dysfunctions are commonly linked to rhythm disturbances such as type 3 Long QT Syndrome (LQTS), Brugada Syndrome (BrS), Sick Sinus Syndrome (SSS), or conduction defects (Amin et al., 2010), dysfunctions of this protein have also been linked to a morphological defect (Gosselin-Badaroudine et al., 2012b). Interestingly, the phenotype observed in cases of DCM-linked SCN5A mutations is a combination of complex arrhythmias and cardiac dilatation. In addition, while mutated $\mathrm{Na}_{\mathrm{v}} 1.5$ proteins cause different biophysical defects, the clinical phenotypes reported clearly show major similarities (Table 3 ). We recently linked the $\mathrm{R} 219 \mathrm{H}$ mutation on the SCN5A to mixed arrhythmias and the DCM phenotype, although the classic biophysical properties of the mutant protein are not affected (Table 3) (GosselinBadaroudine et al., 2012b). We described a 29-year-old patient who suffered from cardiac dilatation associated with complex arrhythmias including bradycardia, atrial flutter, atrio-ventricular block, and tachycardia (Table 3) (Gosselin-Badaroudine et al., $2012 b)$. Since the mutated residue was the first highly conserved arginine on the S4 segment of DI (Figures 2, 6), the lack of alterations to the biophysical properties of the channel led us to search for a gating pore current. Our study revealed that the $\mathrm{R} 219 \mathrm{H}$ mutation induces a proton-specific gating pore current (Gosselin-Badaroudine et al., 2012b). Given the location of the other mutations associated with similar phenotypes (Figure 7), we propose that the generation of gating pore currents may be the common underlying mechanism that links all the phenotypes
(Table 3) (Gosselin-Badaroudine et al., 2013). While all the mutations are not located on the S4 segment, mutations on the S1, S2, or S3 segment may allow the water crevices to communicate and induce gating pore currents (Figure 7).

In a recent review, Jurkat-Rott et al. classified the R225Q/W and R814Q SCN5A mutations as type 3 LQTS (Jurkat-Rott et al., 2012). They proposed that the substitution of these highly conserved arginines on the S4 segment (Figure 2) creates a gating pore. Interestingly, the original articles describing these mutations report that LQTS is associated with other arrhythmias and heart morphology abnormalities (Bezzina et al., 2003; Frigo et al., 2007). Here again, the presence of gating pores due to the mutations was not investigated.

The molecular mechanisms for the pathogenic process leading to the development of this complex pathology may be similar to the process observed in HypoPP (Figure 8). The $\mathrm{H}^{+}$leak (or possibly non-specific cation leak) might imbalance the $\mathrm{V}_{\mathrm{REST}}$ of cardiomyocytes and trigger the arrhythmias. Intracellular acidification may also have an impact on connexin conductance, uncoupling intercellular communication (Bukauskas et al., 2001). The cardiac remodeling may be due to the major imbalance in ionic homeostasis. Gating pore currents, combined with the activity of numerous exchangers, may thus cause significant changes in $\mathrm{Na}^{+}$, $\mathrm{Ca}^{2+}$, and $\mathrm{H}^{+}$concentrations, which would decrease the affinity of troponin for $\mathrm{Ca}^{2+}$ (Figure 8). Cardiac contraction disturbances have been reported to result from alterations to the affinity of troponin for $\mathrm{Ca}^{2+}$ (Liu et al., 2012). This would lead to a reduction in contractile strength, which in turn would result in an impaired ejection fraction. Moreover, the uncoupling of sarcomeric proteins may have an impact on the cellular structure, leading to cardiac remodeling and DCM.

However, this cardiac remodeling may also be the result of weakened contractions in a background of normal blood pressure on the heart walls. Unfortunately, the morphological structure of cardiomyocytes has not been studied in great depth, which limits our understanding of the pathological processes. Lastly, gating pore currents caused by other $\mathrm{Na}_{\mathrm{v}} 1.5$ mutations (Figure 7) need to be recorded to confirm that gating pore currents are a common mechanism linked to the development of familial DCM.

\section{PERIPHERAL NERVE HYPEREXCITABILITY}

Peripheral nerve hyperexcitability (PNH), also known as neuromyotonia, is a motor neuron dysfunction with heterogeneous clinical symptoms. PNH has a prevalence of $<1$ in 1 million. Two main subtypes of $\mathrm{PNH}$ can be distinguished, i.e., the autoimmune and the non-autoimmune form. Among the non-autoimmune forms, 2 of the 3 subtypes of hereditary PNH are channelopathies. The most common symptoms include skeletal muscle overactivity, muscle twitching and painful cramps (Jurkat-Rott et al., 2010).

The KCNQ2 gene encodes the $\mathrm{K}_{\mathrm{V}} 7.2 \mathrm{~K}^{+}$channel which contributes to the neuronal non-inactivating M-current (Cannon, 2006). These $K_{v} 7.2$ channels are broadly expressed in the brain and the spinal cord (Schroeder et al., 1998; Dedek et al., 2001). In physiological conditions, $\mathrm{K}_{\mathrm{v}} 7.2$ channels are co-expressed with $\mathrm{K}_{\mathrm{V}} 7.3$ channels to form heterotetramers responsible for the $\mathrm{M}$ current. The slow opening of these channels mainly sets the 


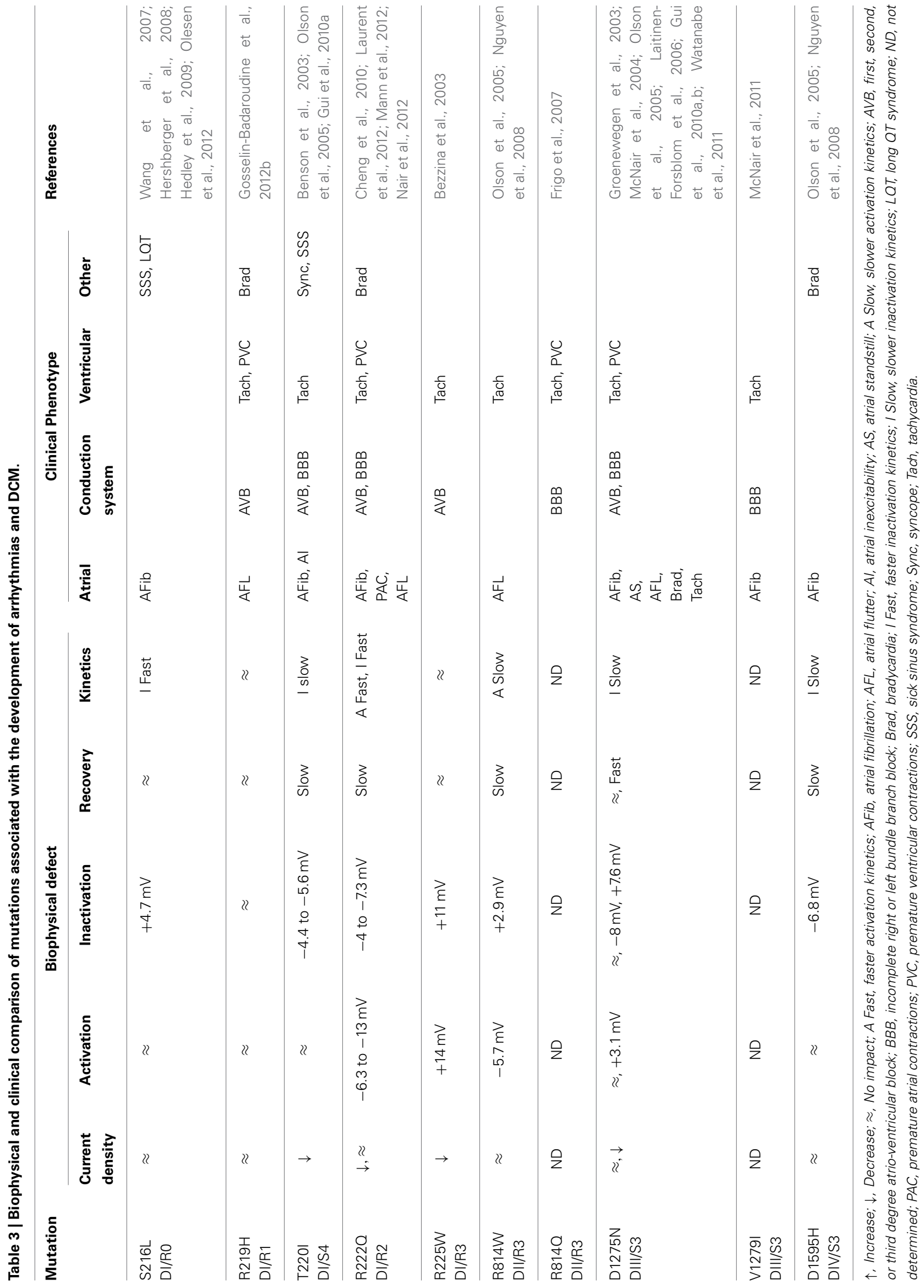


resting membrane potential and thus modulates the neuronal firing frequency (Hernandez et al., 2008). Most known mutations of the $\mathrm{K}_{\mathrm{v}} 7.2$ channel are associated with the development of neonatal epilepsy known as benign familial neonatal convulsion (BFNC). These $\mathrm{K}_{\mathrm{v}} 7.2$ mutations are mainly localized in the $\mathrm{PD}$, the intra and cellular loops. The contribution of this channel to the disease manifestation could thus be due to its role in setting the neuronal resting membrane potential (Lerche et al., 2005).

Recent reports suggest that $K_{v} 7.2$ mutations in the channel's VSD may be associated with other clinical phenotypes (Dedek et al., 2001; Wuttke et al., 2007). The R207W and R207Q mutations result in the neutralization of the fourth conserved arginine of the VSD's S4 segment (R4W and R4Q). The R207W mutation has been linked to the development of a BFNC phenotype associated with PNH (Dedek et al., 2001). The similar R207Q mutation has been linked to PNH without BFNC (Wuttke et al., 2007).

The R207W biophysical characterization revealed that the mutation causes a depolarizing shift in the voltage-dependence and a drastic slowing of activation resulting in a loss of channel function. This would probably explain the BFNC and PHN phenotype (Dedek et al., 2001). When $\mathrm{K}_{\mathrm{v}} 7.2$ and $\mathrm{K}_{\mathrm{v}} 7.3$ were co-expressed to potentially mimic a probable physiological condition, this loss of channel function due to the R207W mutation is still observed (Dedek et al., 2001).

The investigation of the R207Q mutation also revealed a loss of channel function via similar mechanisms (Wuttke et al., 2007). However, this loss of channel function disappeared in conditions potentially mimicking the situation of a patient carrying the R207Q mutation (co-expression of $\mathrm{K}_{\mathrm{v}} 7.2 / \mathrm{R} 207 \mathrm{Q}, \mathrm{K}_{\mathrm{v}} 7.2 / \mathrm{WT}$, and $\mathrm{K}_{\mathrm{v}} 7.3$ subunit) (Wuttke et al., 2007).

The localization of R207Q and R207W mutations led the researchers to suspect and then confirm the presence of gating pore current. Due to low $\mathrm{K}_{\mathrm{v}} 7.2$ channel expression, the presence of gating pore current was investigated in homologous $\mathrm{K}_{\mathrm{v}} 7.4$ channels. It was thus found that reproducing the R207Q or $\mathrm{R} 207 \mathrm{~W}$ mutations caused the creation of a gating pore. Since this channel is similar to the $\mathrm{K}_{\mathrm{v}} 7.2$ channel, it is reasonable to assume that the gating pore current observed in $\mathrm{K}_{\mathrm{v}} 7.4$ would be similar in $\mathrm{K}_{\mathrm{v}} 7.2$ channels.

Therefore, the common PNH phenotype observed could be due to the gating pore current induced by the R207W/Q mutations. Indeed, in conditions close to the physiology, the R207Q mutation did not seem to change channel's function while the R207W mutation induced a loss of channel function (Wuttke et al., 2007). This might thus explain why the BFNC phenotype is observed with the R207W mutation whereas the R207Q mutation only causes PNH.

The pathophysiological process could be similar to the one observed with the R675W mutation (R3W) of the $\mathrm{Na}_{\mathrm{v}} 1.4$ isoform causing NormoPP previously discussed. The $\mathrm{Na}^{+}$leak caused by gating pore currents could facilitate the generation of action potentials by lowering the threshold, thus leading to neuronal hyperexcitability.

\section{OTHER GATING PORE LINKED PATHOLOGIES}

To date, HypoPP, NormoPP, arrhythmic familial DCM and PNH are the only pathologies that have been clearly associated with gating pore currents. However, recent reports, based solely on the location of the mutation, have indicated that other pathologies may be linked to gating pore currents. A total of 28 mutations on the $\mathrm{S} 4$ segments of $\mathrm{Na}_{\mathrm{v}}, \mathrm{Ca}_{\mathrm{v}}$, and $\mathrm{K}_{\mathrm{v}}$ have been described. These mutations cause six other pathologies (LQTS, familial hemiplegic migraine, epilepsy, benign familial neonatal infantile seizures, familial episodic pain, and malignant hyperthermia susceptibility) (Figure 7) (Scalmani et al., 2006; Striessnig et al., 2010; Jurkat-Rott et al., 2012; Zhang et al., 2013). However, the association between gating pores and these pathologies are hypothetical and more studies are required to confirm the presence of gating pores. As such, these assumptions should be treated with caution. Similar assumptions have been made about the R1448C and R1448H Nav 1.4 mutations (R1-S4/DIV) (Sokolov et al., 2007). These mutations have been linked to the occurrence of paramyotonia congenital (Chahine et al., 1994b). Gating pore currents should appear, based on the location of the mutation (first arginine on S4 of DIV). However, the R1448C mutation does not induce a gating pore current (Francis et al., 2011), which was recently confirmed by Gosselin-Badaroudine et al. (2012a). It is thus far from certain that a given mutation will induce a gating pore current based solely on the site of the mutation.

\section{PHARMACOLOGY BLOCKERS AS RESEARCH TOOLS}

A few gating pore blockers have been tentatively identified. However, due to the wide diversity of the immediate environment of gating pores, no universal blocker has yet been identified.

Divalent cations such as barium $\left(\mathrm{Ba}^{2+}\right)$, zinc $\left(\mathrm{Zn}^{2+}\right)$, and $\mathrm{Ca}^{2+}$ are effective in the millimolar (mM) range (Table 4). These cations block gating pores created by the arginine-to-glycine substitution of the second arginine of the S4 segment in DII of $\mathrm{Na}_{\mathrm{v}} 1.4$ (R666G) (Sokolov et al., 2007). Nickel $\left(\mathrm{Ni}^{2+}\right)$, cadmium $\left(\mathrm{Cd}^{2+}\right)$, and barium $\left(\mathrm{Ba}^{2+}\right)$, on the other hand, do not block gating pores created by the $\mathrm{R} 663 \mathrm{H}$ mutation in $\mathrm{Na}_{\mathrm{v}} 1.4$ (Table 4) (Struyk and Cannon, 2007). Possible explanations include the location of the mutation and the nature of the gating pore current since gating pores induced by the R666 mutation conduct monovalent cations while the $\mathrm{R} 663 \mathrm{H}$ mutant channel specifically conducts $\mathrm{H}^{+}$.

Conflicting results have been published. Sokolov et al. studied the $\mathrm{R} 666 \mathrm{G}$ mutation in $\mathrm{Na}_{\mathrm{v}} 1.4$ and reported that gating pores can be blocked by divalent cations (Sokolov et al., 2007) while Struyk et al. reported that divalent cations do not block gating pores (Table 4) (Struyk et al., 2008). This result was the subject of some debate until it was discovered that divalent cations do indeed block gating pores created by the R666G mutation in a voltage-dependent manner (Sokolov et al., 2010). Trivalent and quadrivalent ions (gadolinium $\mathrm{Gd}^{3+}$, ytterbium $\mathrm{Yb}^{3+}$, lanthanum $\mathrm{La}^{3+}$, lutetium $\mathrm{Lu}^{3+}$, yttrium $\mathrm{Y}^{3+}$, titanium $\mathrm{Ti}^{3+}$, and hafnium $\mathrm{Hf}^{4+}$ ) have also been reported to block gating pores, but in a voltage-independent manner (Sokolov et al., 2010).

The arginine residue can be considered as a natural gating pore blocker since gating pore currents appear following the substitution of the arginine on the S4 segment of VSDs (Figures 3, 4). Some researchers are thus investigating molecules derived from the side chain of arginine as blockers. The arginine side chain 
Table 4 | lons and molecules tested as gating pore blockers.

\begin{tabular}{|c|c|c|c|c|c|c|c|}
\hline Channel & Mutation & Location & \multicolumn{2}{|c|}{ lons } & \multicolumn{2}{|c|}{ Guanidinium derivatives } & References \\
\hline dShaker & $\mathrm{R} 362 \mathrm{C} / \mathrm{E} 283 \mathrm{D}$ & R1/E1 & $\mathrm{Mg}^{2+}$ & & Ethyl-guanidium & & Tombola et al., 2005 \\
\hline $\mathrm{rNa}_{\mathrm{v}} 1.4$ & R666G & DII/R2 & $\mathrm{Ca}^{2+}, \mathrm{Zn}^{2+}, \mathrm{Ba}^{2+}$ & & & & Sokolov et al., 2007 \\
\hline $\mathrm{rNa} \mathrm{ra}_{\mathrm{v}} 1.4$ & $\mathrm{R} 663 \mathrm{H}$ & DII/R1 & & $\begin{array}{l}\mathrm{Li}^{+}, \mathrm{Ni}^{2+}, \mathrm{Cd}^{2+} \\
\mathrm{Ba}^{2+}\end{array}$ & & & $\begin{array}{l}\text { Struyk and Cannon, } \\
2007\end{array}$ \\
\hline $\mathrm{rNa}_{\mathrm{v}} 1.4$ & R666G & DII/R2 & $\begin{array}{l}\mathrm{Ca}^{2+}, \mathrm{Zn}^{2+}, \mathrm{Y}^{3+} \\
\mathrm{Ba}^{2+}, \mathrm{La}^{3+}, \mathrm{Yb}^{3+} \\
\mathrm{Lu}^{3+}, \mathrm{Hf}^{4+}, \mathrm{Tl}^{3+}\end{array}$ & & $\begin{array}{l}\text { 1-(2,4-xylyl) } \\
\text { guanidine-carbonate }\end{array}$ & $\begin{array}{l}\text { Ethyl- } \\
\text { guanidium }\end{array}$ & Sokolov et al., 2010 \\
\hline$h H_{v} 1$ & R211S & R3 & $\mathrm{Zn}^{2+}$ & & & & $\begin{array}{l}\text { Berger and Isacoff, } \\
2011\end{array}$ \\
\hline
\end{tabular}

${ }^{*}$ For N.at-K $K_{v} 3.2$, no substitution was required to induce a gating pore.

contains a guanidine. Interestingly, guanidinium ions permeate through gating pores while guanidinium derivatives such as ethylguanidinium and 1-(2,4-xylyl) guanidine carbonate have been reported to block gating pores (Table 4) (Tombola et al., 2005; Sokolov et al., 2010).

Gating pore blockers can be useful research tools, but the variability in published data is puzzling. Several investigators have reported that divalent and trivalent cations can block gating pores (Sokolov et al., 2007, 2010; Wu et al., 2011), while others have reported the opposite (Table 4) (Struyk and Cannon, 2007; Francis et al., 2011; Gosselin-Badaroudine et al., 2012b). This discrepancy may be due to differences in the environments surrounding the gating pores. However, investigators studying the same mutation have reported opposite results (Sokolov et al., 2007; Struyk et al., 2008) In this case, the discrepancy may be due to differences in the experimental methods (Sokolov et al., 2010). The voltage-dependence of the block may also explain the discrepancy. New studies are needed to clarify this issue.

Gating modifier toxins can also be useful in fundamental research. These toxins can stabilize the VSDs of various ion channels in their resting or activated state. Six toxin binding sites (sites 1-6) have been identified in $\mathrm{Na}_{\mathrm{v}}$, with site 4 located in the VSD of DII (Cestele and Catterall, 2000). Toxins that affect site 4 can be used to modulate ion permeation through gating pores. For example, toxins in the same category as $\beta$-scorpion and $\beta$-spider toxins, including Css4 (Centruroides suffusus suffusus toxin 4), Ts $\gamma$ (Tityus serrulatus gamma toxin), Lqh $\beta 1$ (Leiurus quinquestriatus hebraeus Beta 1 toxin), AahIT (Androctonus australis Hector Insect Toxin), and Magi 5 (Macrothele gigas toxin 5) stabilize VSDs in their activated state (Martin et al., 1987; Chahine et al., 1998; Possani et al., 1999; Corzo et al., 2003; Stevens et al., 2011). In contrast, toxins such as $\mu$-Oconotoxins (MrVIA and MrVIB) as well as HWTX-IV (Huwentoxin-IV) have the same binding site as $\beta$-scorpion toxins (site 4), but stabilize VSDs in their resting state (Leipold et al., 2007; Xiao et al., 2008).

\section{TARGETING VSDS AS A THERAPEUTIC APPROACH}

None of the reported gating pore blockers has been shown to be clinically relevant. When the pathology is known to be caused by gating pore currents, patients only benefit from symptomatic treatment targeting the downstream consequences of the mutation (paralysis or arrhythmias). Before a gating pore blocker can be used on a given patient, its effectiveness has to be verified in vitro on the patient's specific mutation. This is of critical importance since there are no known universal gating pore blockers. Most drugs target the central alpha pore. However, the fact that gating pore currents play a role in pathogenic processes will help in the development of new therapies that target VSDs. For example, molecules such as NH29 (a diclofenac derivative), a gating modifier that promotes the opening of the $\mathrm{K}_{\mathrm{v}} 7.2$ channel (Peretz et al., 2007, 2010), could be a starting point for the development of new drugs.

Given the diversity of the mutations, targeting VSDs could be an effective strategy for sidestepping the variability of the mutations (nature of the mutations, nature of the pathological current, voltage dependence). Modulating VSDs would stabilize a given mutated S4 segment in the activated or resting state in order to prevent water crevices from communicating and, as such, prevent gating pore currents. For example, $\beta$-scorpion toxins bind to site 4 on the $\mathrm{Na}_{\mathrm{v}}$ channel and stabilize the S4 segment of DII in its activated state (Catterall et al., 2007). Unfortunately, the precise impact of each S4 segment and their possible cooperation in the gating of the alpha pores of the $\mathrm{Na}_{\mathrm{v}}$ and $\mathrm{Ca}_{\mathrm{v}}$ channels need to be clarified. Maintaining the gating properties and alpha pore functions of channels is a major challenge for developing therapies to specifically treat gating pore current-induced pathologies. So far, only 1-(2,4-xylyl) guanidine carbonate (Table 4) appears to be an efficient, specific blocker that could be used on most gating pores, especially since it does not modify the gating properties of the alpha pore (Sokolov et al., 2010). It would be very interesting to test 1-(2,4-xylyl) guanidine carbonate in the two transgenic 
animal models of HypoPP (Wu et al., 2011, 2012) in which the phenotype is caused by a $\mathrm{Na}_{\mathrm{v}} 1.4$ mutation in one model and a $\mathrm{Ca}_{\mathrm{v}} 1.1$ mutation in the other. It would also allow the blocker to be tested on different gating pores.

Developing approaches to modulate VSDs to treat channelopathies should also be considered. Even if such studies reveal that changing gating properties should be avoided in the case of gating pore currents, they could lead to new therapeutic avenues for treating cell excitability disorders and channelopathies such as LQTS and BrS. In addition, therapies that prevent the activation of specific $\mathrm{Na}_{\mathrm{v}}\left(\mathrm{Na}_{\mathrm{v}} 1.7\right.$ or $\left.\mathrm{Na}_{\mathrm{v}} 1.8\right)$ channels might also be valuable in treating pain while avoiding the addictive side effect of currently available drugs.

\section{PERSPECTIVES AND CONCLUSIONS}

The recent discovery of gating pore currents provides a fresh perspective in the field of electrophysiology. Gating pores are a promising new tool for the investigation of VSD structures and functions. Only a few crystal structures of VGICs have been reported. Moreover, the structures of only six TM channels have been elucidated (Jiang et al., 2003; Long et al., 2005, 2007; McCusker et al., 2012; Payandeh et al., 2012; Zhang et al., 2012). Gating pore currents are thus a powerful tool for investigating similarities and differences between VSDs. Simulations based on existing crystal structures have been used to understand and predict the complex tridimensional structures of $\mathrm{Na}_{\mathrm{v}}$ and $\mathrm{Ca}_{\mathrm{v}}$ channels (Tao et al., 2010; Delemotte et al., 2011; KhaliliAraghi et al., 2012). Gating pore currents could be used to provide restrictive criteria to build computational models that more closely mimic physiological conditions. Gating pores have also been studied to better understand the environment (hydrophilic and hydrophobic) and functioning (sequence of activation of the various domains, movement of the S4 segment) of VGICs.

To date, four phenotypes have been clearly associated with the appearance of gating pore currents (HypoPP, NormoPP, arrhythmic DCM and PNH). These pathologies are caused by mutations on $\mathrm{Na}_{\mathrm{v}}, \mathrm{Ca}_{\mathrm{v}}$ or $\mathrm{K}_{\mathrm{v}}$ channels. However, suitable environments for the creation of gating pores can be found in most proteins containing a VSD. It is thus surprising that gating pore currents have only been detected in one pathology associated with $\mathrm{K}_{\mathrm{v}}$ channel mutations. This may be due to the relative novelty of gating pores or to the highly deleterious impact of gating pore currents induced by the tetrameric nature of $\mathrm{K}_{\mathrm{v}}$ channels. Similar hypothesis might explain why only few mutations located on the S2 or S3 segments of VSDs have been related to the development pathological phenotypes. Such mutations in the GCTC would also disrupt interactions between the GCTC and the S4 segment leading to the appearance of a gating pore current. The resulting gating pore would be constitutively activated as the interactions between the GCTC and the S4 segment would be disrupted for all the possible states of the VSD. Nevertheless, this phenomenon has never been observed and remains to be elucidated.

Future discoveries might reveal pathologies caused by the disappearance of gating pore currents. Indeed mutations that abolish or modify the currents carried by $\mathrm{H}_{\mathrm{v}} \mathrm{l}$ channels might lead to the discovery of an association with various pathologies given their broad distribution.
Lastly, gating pore currents are a novelty in the field of VGICs and are a promising tool for structure-function investigations. Studies on gating pore currents provide new insights into familial diseases and may help identify the causes of various pathologies and, as such, the development of new therapeutic approaches.

\section{ACKNOWLEDGMENTS}

This study was supported by grants from the Heart and Stroke Foundation of Quebec (HSFQ), the Canadian Institutes of Health Research (CIHR, MOP-111072 and MOP-130373).

\section{REFERENCES}

Amin, A. S., Asghari-Roodsari, A., and Tan, H. L. (2010). Cardiac sodium channelopathies. Pflugers Arch 460, 223-237. doi: 10.1007/s00424-009-0761-0

Armstrong, C. M., and Bezanilla, F. (1973). Currents related to movement of the gating particles of the sodium channels. Nature 242, 459-461. doi: 10.1038/242459a0

Ball, K. L., Johnson, M. D., and Solaro, R. J. (1994). Isoform specific interactions of troponin I and troponin $\mathrm{C}$ determine $\mathrm{pH}$ sensitivity of myofibrillar Ca2+ activation. Biochemistry 33, 8464-8471. doi: 10.1021/bi0019 $4 \mathrm{a} 010$

Benson, D. W., Wang, D. W., Dyment, M., Knilans, T. K., Fish, F. A., Strieper, M. J., et al. (2003). Congenital sick sinus syndrome caused by recessive mutations in the cardiac sodium channel gene (SCN5A). J. Clin. Invest. 112, 1019-1028. doi: 10.1172/JCI200318062

Berger, T. K., and Isacoff, E. Y. (2011). The pore of the voltage-gated proton channel. Neuron 72, 991-1000. doi: 10.1016/j.neuron.2011.11.014

Bezzina, C. R., Rook, M. B., Groenewegen, W. A., Herfst, L. J., Van Der Wal, A. C., Lam, J., et al. (2003). Compound heterozygosity for mutations (W156X and $\mathrm{R} 225 \mathrm{~W}$ ) in SCN5A associated with severe cardiac conduction disturbances and degenerative changes in the conduction system. Circ. Res. 92, 159-168. doi: 10.1161/01.RES.0000052672.97759.36

Bukauskas, F. F., Bukauskiene, A., Bennett, M. V., and Verselis, V. K. (2001). Gating properties of gap junction channels assembled from connexin 43 and connexin43 fused with green fluorescent protein. Biophys. J. 81, 137-152. doi: 10.1016/S0006-3495(01)75687-1

Campos, F. V., Chanda, B., Roux, B., and Bezanilla, F. (2007). Two atomic constraints unambiguously position the $\mathrm{S} 4$ segment relative to $\mathrm{S} 1$ and $\mathrm{S} 2$ segments in the closed state of Shaker K channel. Proc. Natl. Acad. Sci. U.S.A. 104, 7904-7909. doi: 10.1073/pnas.0702638104

Cannon, S. C. (2006). Pathomechanisms in channelopathies of skeletal muscle and brain. Annu. Rev. Neurosci. 29, 387-415. doi: 10.1146/annurev.neuro.29.051605.112815

Cannon, S. C. (2010). Voltage-sensor mutations in channelopathies of skeletal muscle. J. Physiol. 588, 1887-1895. doi: 10.1113/jphysiol.2010.186874

Capasso, M., Decoursey, T. E., and Dyer, M. J. (2011). pH regulation and beyond: unanticipated functions for the voltage-gated proton channel, HVCN1. Trends Cell Biol. 21, 20-28. doi: 10.1016/j.tcb.2010.09.006

Catterall, W. A. (1986). Molecular properties of voltage-sensitive sodium channels. Annu. Rev. Biochem. 55, 953-985. doi: 10.1146/annurev.bi.55.070186.004513

Catterall, W. A., Cestele, S., Yarov-Yarovoy, V., Yu, F. H., Konoki, K., and Scheuer, T. (2007). Voltage-gated ion channels and gating modifier toxins. Toxicon 49, 124-141. doi: 10.1016/j.toxicon.2006.09.022

Cestele, S., and Catterall, W. A. (2000). Molecular mechanisms of neurotoxin action on voltage-gated sodium channels. Biochimie 82, 883-892. doi: 10.1016/S03009084(00)01174-3

Chahine, M., Bennett, P. B., George, A. L. Jr., and Horn, R. (1994a). Functional expression and properties of the human skeletal muscle sodium channel. Pflugers Arch 427, 136-142. doi: 10.1007/BF00585952

Chahine, M., George, A. L. Jr., Zhou, M., Ji, S., Sun, W., Barchi, R. L., et al. (1994b). Sodium channel mutations in paramyotonia congenita uncouple inactivation from activation. Neuron 12, 281-294. doi: 10.1016/0896-6273(94)90271-2

Chahine, M., Sirois, J., Marcotte, P., Chen, L., and Kallen, R. G. (1998). Extrapore residues of the S5-S6 loop of domain 2 of the voltage-gated skeletal muscle sodium channel (rSkM1) contribute to the mu-conotoxin GIIIA binding site. Biophys. J. 75, 236-246. doi: 10.1016/S0006-3495(98)77510-1 
Chanda, B., and Bezanilla, F. (2002). Tracking voltage-dependent conformational changes in skeletal muscle sodium channel during activation. J. Gen. Physiol. 120, 629-645. doi: 10.1085/jgp.20028679

Cheng, J., Morales, A., Siegfried, J. D., Li, D., Norton, N., Song, J., et al. (2010). SCN5A rare variants in familial dilated cardiomyopathy decrease peak sodium current depending on the common polymorphism H558R and common splice variant Q1077del. Clin. Trans. Sci. 3, 287-294. doi: 10.1111/j.17528062.2010.00249.x

Cherny, V. V., Murphy, R., Sokolov, V., Levis, R. A., and Decoursey, T. E. (2003). Properties of single voltage-gated proton channels in human eosinophils estimated by noise analysis and by direct measurement. J. Gen. Physiol. 121, 615-628. doi: 10.1085/jgp.200308813

Corzo, G., Gilles, N., Satake, H., Villegas, E., Dai, L., Nakajima, T. et al.(2003). Distinct primary structures of the major peptide toxins from the venom of the spider Macrothele gigas that bind to sites 3 and 4 in the sodium channel. FEBS Lett. 547, 43-50. doi: 10.1016/S0014-5793(03)00666-5

Decoursey, T. E. (2003). Voltage-gated proton channels and other proton transfer pathways. Physiol. Rev. 83, 475-579. doi: 10.1152/physrev.00028.2002

Decoursey, T. E. (2013). Voltage-gated proton channels: molecular biology, physiology, and pathophysiology of the HV family. Physiol. Rev. 93, 599-652. doi: 10.1152/physrev.00011.2012

Dedek, K., Kunath, B., Kananura, C., Reuner, U., Jentsch, T. J., and Steinlein, O. K. (2001). Myokymia and neonatal epilepsy caused by a mutation in the voltage sensor of the KCNQ2 K+ channel. Proc. Natl. Acad. Sci. U.S.A. 98, 12272-12277. doi: 10.1073/pnas.211431298

Delemotte, L., Tarek, M., Klein, M. L., Amaral, C., and Treptow, W. (2011). Intermediate states of the Kv1.2 voltage sensor from atomistic molecular dynamics simulations. Proc. Natl. Acad. Sci. U.S.A. 108, 6109-6114. doi: 10.1073/pnas. 1102724108

Doyle, D. A., Morais Cabral, J., Pfuetzner, R. A., Kuo, A., Gulbis, J. M., Cohen, S. L., et al. (1998). The structure of the potassium channel: molecular basis of $\mathrm{K}+$ conduction and selectivity. Science 280, 69-77. doi: 10.1126/science.280.5360.69

Eisenman, G. (1962). Cation selective glass electrodes and their mode of operation. Biophys. J. 2, 259-323. doi: 10.1016/S0006-3495(62)86959-8

El Chemaly, A., Guinamard, R., Demion, M., Fares, N., Jebara, V., Faivre, J. F., et al. (2006). A voltage-activated proton current in human cardiac fibroblasts. Biochem. Biophys. Res. Commun. 340, 512-516. doi: 10.1016/j.bbrc.2005.12.038

Fabiato, A., and Fabiato, F. (1978). Effects of $\mathrm{pH}$ on the myofilaments and the sarcoplasmic reticulum of skinned cells from cardiace and skeletal muscles. J. Physiol. 276, 233-255.

Fan, C., Lehmann-Horn, F., Weber, M. A., Bednarz, M., Groome, J. R., Jonsson, M. K., et al. (2013). Transient compartment-like syndrome and normokalaemic periodic paralysis due to a Cav1.1 mutation. Brain 136, 3775-3786. doi: 10.1093/brain/awt300

Francis, D. G., Rybalchenko, V., Struyk, A., and Cannon, S. C. (2011). Leaky sodium channels from voltage sensor mutations in periodic paralysis, but not paramyotonia. Neurology 76, 1635-1641. doi: 10.1212/WNL.0b013e31 $8219 \mathrm{fb} 57$

Frigo, G., Rampazzo, A., Bauce, B., Pilichou, K., Beffagna, G., Danieli, G. A., et al. (2007). Homozygous SCN5A mutation in Brugada syndrome with monomorphic ventricular tachycardia and structural heart abnormalities. Europace 9, 391-397. doi: 10.1093/europace/eum053

Gamal El-Din, T. M., Heldstab, H., Lehmann, C., and Greeff, N. G. (2010). Double gaps along Shaker S4 demonstrate omega currents at three different closed states. Channels (Austin) 4, 93-100. doi: 10.4161/chan.4.2.10672

Ge, J., Sun, A., Paajanen, V., Wang, S., Su, C., Yang, Z., et al. (2008). Molecular and clinical characterization of a novel SCN5A mutation associated with atrioventricular block and dilated cardiomyopathy. Circ. Arrhythm. Electrophysiol. 1, 83-92. doi: 10.1161/CIRCEP.107.750752

Gellens, M. E., George, A. L. Jr., Chen, L. Q., Chahine, M., Horn, R., Barchi, R. L., et al. (1992). Primary structure and functional expression of the human cardiac tetrodotoxin-insensitive voltage-dependent sodium channel. Proc. Natl. Acad. Sci. U.S.A. 89, 554-558. doi: 10.1073/pnas.89.2.554

Gosselin-Badaroudine, P., Delemotte, L., Moreau, A., Klein, M. L., and Chahine, M. (2012a). Gating pore currents and the resting state of Nav1.4 voltage sensor domains. Proc. Natl. Acad. Sci. U.S.A. 109, 19250-19255. doi: 10.1073/pnas. 1217990109

Gosselin-Badaroudine, P., Keller, D. I., Huang, H., Pouliot, V., Chatelier, A., Osswald, S., et al. (2012b). A proton leak current through the cardiac sodium channel is linked to mixed arrhythmia and the dilated cardiomyopathy phenotype. PLoS ONE 7:e38331. doi: 10.1371/journal.pone.0038331

Gosselin-Badaroudine, P., Moreau, A., and Chahine, M. (2013). Na 1.5 mutations linked to dilated cardiomyopathy phenotypes: is the gating pore current the missing link? Channels (Austin) 8. doi: 10.4161/chan.27179

Groenewegen, W. A., Firouzi, M., Bezzina, C. R., Vliex, S., Van Langen, I. M., Sandkuijl, L., et al. (2003). A cardiac sodium channel mutation cosegregates with a rare connexin40 genotype in familial atrial standstill. Circ. Res. 92, 14-22. doi: 10.1161/01.RES.0000050585.07097.D7

Groome, J. R., Lehmann-Horn, F., Fan, C., Wolf, M., Winston, V., Merlini, L., et al. (2014). NaV1.4 mutations cause hypokalaemic periodic paralysis by disrupting IIIS4 movement during recovery. Brain 137, 998-1008. doi: 10.1093/brain/awu015

Gui, J., Wang, T., Jones, R. P., Trump, D., Zimmer, T., and Lei, M. (2010a). Multiple loss-of-function mechanisms contribute to SCN5A-related familial sick sinus syndrome. PLoS ONE 5:e10985. doi: 10.1371/journal.pone.0010985

Gui, J., Wang, T., Trump, D., Zimmer, T., and Lei, M. (2010b). Mutation-specific effects of polymorphism H558R in SCN5A-related sick sinus syndrome. $J$. Cardiovasc. Electrophysiol. 21, 564-573. doi: 10.1111/j.1540-8167.2010.01762.x

Guy, H. R., and Seetharamulu, P. (1986). Molecular model of the action potential sodium channel. Proc. Natl. Acad. Sci. U.S.A. 83, 508-512. doi: 10.1073/pnas.83.2.508

Hedley, P. L., Jorgensen, P., Schlamowitz, S., Wangari, R., Moolman-Smook, J., Brink, P. A., et al. (2009). The genetic basis of long QT and short QT syndromes: a mutation update. Hum. Mutat. 30, 1486-1511. doi: 10.1002/humu.21106

Heinemann, S. H., Terlau, H., Stuhmer, W., Imoto, K., and Numa, S. (1992). Calcium channel characteristics conferred on the sodium channel by single mutations. Nature 356, 441-443. doi: 10.1038/356441a0

Hernandez, C. C., Zaika, O., Tolstykh, G. P., and Shapiro, M. S. (2008). Regulation of neural KCNQ channels: signalling pathways, structural motifs and functional implications. J. Physiol. 586, 1811-1821. doi: 10.1113/jphysiol.2007.148304

Hershberger, R. E., Parks, S. B., Kushner, J. D., Li, D., Ludwigsen, S., Jakobs, P., et al. (2008). Coding sequence mutations identified in MYH7, TNNT2, SCN5A, CSRP3, LBD3, and TCAP from 313 patients with familial or idiopathic dilated cardiomyopathy. Clin. Trans. Sci. 1, 21-26. doi: 10.1111/j.17528062.2008.00017.x

Hershberger, R. E., and Siegfried, J. D. (2011). Update 2011: clinical and genetic issues in familial dilated cardiomyopathy. J. Am. Coll. Cardiol. 57, 1641-1649. doi: 10.1016/j.jacc.2011.01.015

Hibino, H., Inanobe, A., Furutani, K., Murakami, S., Findlay, I., and Kurachi, Y. (2010). Inwardly rectifying potassium channels: their structure, function, and physiological roles. Physiol. Rev. 90, 291-366. doi: 10.1152/physrev.00021.2009

Hilgemann, D. W., Yaradanakul, A., Wang, Y., and Fuster, D. (2006). Molecular control of cardiac sodium homeostasis in health and disease. J Cardiovasc. Electrophysiol. 17(Suppl. 1), S47-S56. doi: 10.1111/j.1540-8167.2006.00383.x

Hodgkin, A. L., and Huxley, A. F. (1952). A quantitative description of membrane current and its application to conduction and excitation in nerve. J. Physiol. 117, 500-544.

Iwasaki, H., Murata, Y., Kim, Y., Hossain, M. I., Worby, C. A., Dixon, J. E., et al. (2008). A voltage-sensing phosphatase, Ci-VSP, which shares sequence identity with PTEN, dephosphorylates phosphatidylinositol 4,5-bisphosphate. Proc. Natl. Acad. Sci. U.S.A. 105, 7970-7975. doi: 10.1073/pnas.0803936105

Jiang, Y., Lee, A., Chen, J., Ruta, V., Cadene, M., Chait, B. T., et al.(2003). Xray structure of a voltage-dependent $\mathrm{K}+$ channel. Nature 423, 33-41. doi: 10.1038 /nature01580

Jurkat-Rott, K., Groome, J., and Lehmann-Horn, F. (2012). Pathophysiological role of omega pore current in channelopathies. Front. Pharmacol. 3:112. doi: 10.3389/fphar.2012.00112

Jurkat-Rott, K., Lerche, H., Weber, Y., and Lehmann-Horn, F. (2010). Hereditary channelopathies in neurology. Adv. Exp. Med. Biol. 686, 305-334. doi: 10.1007/978-90-481-9485-8_18

Jurkat-Rott, K., Mitrovic, N., Hang, C., Kouzmekine, A., Iaizzo, P., Herzog, J., et al. (2000). Voltage-sensor sodium channel mutations cause hypokalemic periodic paralysis type 2 by enhanced inactivation and reduced current. Proc. Natl. Acad. Sci. U.S.A. 97, 9549-9554. doi: 10.1073/pnas.97.17.9549

Jurkat-Rott, K., Weber, M. A., Fauler, M., Guo, X. H., Holzherr, B. D., Paczulla, A., et al. (2009). K+-dependent paradoxical membrane depolarization and $\mathrm{Na}+$ overload, major and reversible contributors to weakness by ion channel leaks. Proc. Natl. Acad. Sci. U.S.A. 106, 4036-4041. doi: 10.1073/pnas.0811277106 
Khalili-Araghi, F., Tajkhorshid, E., Roux, B., and Schulten, K. (2012). Molecular dynamics investigation of the omega-current in the Kv1.2 voltage sensor domains. Biophys. J. 102, 258-267. doi: 10.1016/j.bpj.2011.10.057

Klassen, T. L., Buckingham, S. D., Atherton, D. M., Dacks, J. B., Gallin, W. J., and Spencer, A. N. (2006). Atypical phenotypes from flatworm Kv3 channels. J. Neurophysiol. 95, 3035-3046. doi: 10.1152/jn.00858.2005

Klassen, T. L., Spencer, A. N., and Gallin, W. J. (2008). A naturally occurring omega current in a Kv3 family potassium channel from a platyhelminth. BMC Neurosci. 9:52. doi: 10.1186/1471-2202-9-52

Kohlhaas, M., Liu, T., Knopp, A., Zeller, T., Ong, M. F., Bohm, M., et al. (2010). Elevated cytosolic $\mathrm{Na}+$ increases mitochondrial formation of reactive oxygen species in failing cardiac myocytes. Circulation 121, 1606-1613. doi: 10.1161/CIRCULATIONAHA.109.914911

Kumanovics, A., Levin, G., and Blount, P. (2002). Family ties of gated pores: evolution of the sensor module. FASEB J. 16, 1623-1629. doi: 10.1096/fj. 02-0238hyp

Laitinen-Forsblom, P. J., Makynen, P., Makynen, H., Yli-Mayry, S., Virtanen, V., Kontula, K., et al. (2006). SCN5A mutation associated with cardiac conduction defect and atrial arrhythmias. J. Cardiovasc. Electrophysiol. 17, 480-485. doi: 10.1111/j.1540-8167.2006.00411.x

Lapie, P., Goudet, C., Nargeot, J., Fontaine, B., and Lory, P. (1996). Electrophysiological properties of the hypokalaemic periodic paralysis mutation $(\mathrm{R} 528 \mathrm{H})$ of the skeletal muscle alpha 1s subunit as expressed in mouse $\mathrm{L}$ cells. FEBS Lett. 382, 244-248. doi: 10.1016/0014-5793(96)00173-1

Laurent, G., Saal, S., Amarouch, M. Y., Beziau, D. M., Marsman, R. F., Faivre, L., et al. (2012). Multifocal ectopic Purkinje-related premature contractions: a new SCN5A-related cardiac channelopathy. J. Am. Coll. Cardiol. 60, 144-156. doi: 10.1016/j.jacc.2012.02.052

Lee, S. C., Kim, H. S., Park, Y. E., Choi, Y. C., Park, K. H., and Kim, D. S. (2009). Clinical diversity of SCN4A-mutation-associated skeletal muscle sodium channelopathy. J. Clin. Neurol. 5, 186-191. doi: 10.3988/jen.2009.5.4.186

Leipold, E., Debie, H., Zorn, S., Borges, A., Olivera, B. M., Terlau, H., et al. (2007). muO conotoxins inhibit $\mathrm{NaV}$ channels by interfering with their voltage sensors in domain-2. Channels (Austin) 1, 253-262.

Lerche, H., Weber, Y. G., Jurkat-Rott, K., and Lehmann-Horn, F. (2005). Ion channel defects in idiopathic epilepsies. Curr. Pharm. Des. 11, 2737-2752. doi: $10.2174 / 1381612054546815$

Lin, M. C., Hsieh, J. Y., Mock, A. F., and Papazian, D. M. (2011). R1 in the Shaker S4 occupies the gating charge transfer center in the resting state. J. Gen. Physiol. 138, 155-163. doi: 10.1085/jgp.201110642

Liu, B., Tikunova, S. B., Kline, K. P., Siddiqui, J. K., and Davis, J. P. (2012). Diseaserelated cardiac troponins alter thin filament $\mathrm{ca}(2+)$ association and dissociation rates. PLoS ONE 7:e38259. doi: 10.1371/journal.pone.0038259

Long, S. B., Campbell, E. B., and Mackinnon, R. (2005). Crystal structure of a mammalian voltage-dependent Shaker family K+ channel. Science 309, 897-903. doi: 10.1126/science.1116269

Long, S. B., Tao, X., Campbell, E. B., and Mackinnon, R. (2007). Atomic structure of a voltage-dependent $\mathrm{K}+$ channel in a lipid membrane-like environment. Nature 450, 376-382. doi: 10.1038/nature06265

Maack, C., Cortassa, S., Aon, M. A., Ganesan, A. N., Liu, T., and O'rourke, B. (2006). Elevated cytosolic $\mathrm{Na}+$ decreases mitochondrial $\mathrm{Ca} 2+$ uptake during excitation-contraction coupling and impairs energetic adaptation in cardiac myocytes. Circ. Res. 99, 172-182. doi: 10.1161/01.RES.0000232546.92777.05

Mann, S. A., Castro, M. L., Ohanian, M., Guo, G., Zodgekar, P., Sheu, A., et al. (2012). R222Q SCN5A mutation is associated with reversible ventricular ectopy and dilated cardiomyopathy. J. Am. Coll. Cardiol. 60, 1566-1573. doi: 10.1016/j.jacc.2012.05.050

Martin, M. F., Garcia Y Perez, L. G., El Ayeb, M., Kopeyan, C., Bechis, G., Jover, E., et al. (1987). Purification and chemical and biological characterizations of seven toxins from the Mexican scorpion, Centruroides suffusus suffusus. J. Biol. Chem. 262, 4452-4459.

McCusker, E. C., Bagneris, C., Naylor, C. E., Cole, A. R., D’avanzo, N., Nichols, C. G., et al. (2012). Structure of a bacterial voltage-gated sodium channel pore reveals mechanisms of opening and closing. Nat. Commun. 3, 1102. doi: 10.1038/ncomms 2077

McNair, W. P., Ku, L., Taylor, M. R., Fain, P. R., Dao, D., Wolfel, E., et al. (2004). SCN5A mutation associated with dilated cardiomyopathy, conduction disorder, and arrhythmia. Circulation 110, 2163-2167. doi: 10.1161/01.CIR.0000144458.58660.BB
McNair, W. P., Sinagra, G., Taylor, M. R., Di Lenarda, A., Ferguson, D. A., Salcedo, E. E., et al. (2011). SCN5A mutations associate with arrhythmic dilated cardiomyopathy and commonly localize to the voltage-sensing mechanism. J. Am. Coll. Cardiol. 57, 2160-2168. doi: 10.1016/j.jacc.2010.09.084

Morrill, J. A., Brown, R. H. Jr., and Cannon, S. C. (1998). Gating of the L-type Ca channel in human skeletal myotubes: an activation defect caused by the hypokalemic periodic paralysis mutation R528H. J. Neurosci. 18, 10320-10334.

Murata, Y., Iwasaki, H., Sasaki, M., Inaba, K., and Okamura, Y. (2005). Phosphoinositide phosphatase activity coupled to an intrinsic voltage sensor. Nature 435, 1239-1243. doi: 10.1038/nature03650

Musset, B., Smith, S. M., Rajan, S., Morgan, D., Cherny, V. V., and Decoursey, T. E. (2011). Aspartate 112 is the selectivity filter of the human voltage-gated proton channel. Nature 480, 273-277. doi: 10.1038/nature10557

Nagle, J. F., and Morowitz, H. J. (1978). Molecular mechanisms for proton transport in membranes. Proc. Natl. Acad. Sci. U.S.A. 75, 298-302. doi: 10.1073/pnas.75.1.298

Nair, K., Pekhletski, R., Harris, L., Care, M., Morel, C., Farid, T., et al. (2012). Escape capture bigeminy: phenotypic marker of cardiac sodium channel voltage sensor mutation R222Q. Heart Rhythm 9, 1681-1688.e1. doi: 10.1016/j.hrthm.2012.06.029

Nguyen, T. P., Wang, D. W., Rhodes, T. H., and George, A. L., Jr. (2008). Divergent biophysical defects caused by mutant sodium channels in dilated cardiomyopathy with arrhythmia. Circ. Res. 102, 364-371. doi: 10.1161/CIRCRESAHA.107.164673

Noda, M., Shimizu, S., Tanabe, T., Takai, T., Kayano, T., Ikeda, T., et al. (1984) Primary structure of Electrophorus electricus sodium channel deduced from cDNA sequence. Nature 312, 121-127. doi: 10.1038/312121a0

Olesen, M. S., Yuan, L., Liang, B., Holst, A. G., Nielsen, N., Nielsen, J. B., et al. (2012). High prevalence of long QT syndrome-associated SCN5A variants in patients with early-onset lone atrial fibrillation. Circ. Cardiovasc. Genet. 5, 450-459. doi: 10.1161/CIRCGENETICS.111.962597

Olson, T. M., Michels, V. V., Ballew, J. D., Reyna, S. P., Karst, M. L., Herron, K. J., et al. (2005). Sodium channel mutations and susceptibility to heart failure and atrial fibrillation. JAMA 293, 447-454. doi: 10.1001/jama.293.4.447

Palmer, S., and Kentish, J. C. (1994). The role of troponin C in modulating the $\mathrm{Ca} 2+$ sensitivity of mammalian skinned cardiac and skeletal muscle fibres. J. Physiol. 480(Pt 1), 45-60.

Parsons, B., Szczesna, D., Zhao, J., Van Slooten, G., Kerrick, W. G., Putkey, J. A., et al. (1997). The effect of $\mathrm{pH}$ on the $\mathrm{Ca} 2+$ affinity of the $\mathrm{Ca} 2+$ regulatory sites of skeletal and cardiac troponin C in skinned muscle fibres. J. Muscle Res. Cell Motil. 18, 599-609. doi: 10.1023/A:1018623604365

Payandeh, J., Gamal El-Din, T. M., Scheuer, T., Zheng, N., and Catterall, W. A. (2012). Crystal structure of a voltage-gated sodium channel in two potentially inactivated states. Nature 486, 135-139. doi: 10.1038/nature11077

Peretz, A., Degani-Katzav, N., Talmon, M., Danieli, E., Gopin, A., Malka, E., et al. (2007). A tale of switched functions: from cyclooxygenase inhibition to Mchannel modulation in new diphenylamine derivatives. PLoS ONE 2:e1332. doi: 10.1371/journal.pone.0001332

Peretz, A., Pell, L., Gofman, Y., Haitin, Y., Shamgar, L., Patrich, E., et al. (2010). Targeting the voltage sensor of Kv7.2 voltage-gated K+ channels with a new gating-modifier. Proc. Natl. Acad. Sci. U.S.A. 107, 15637-15642. doi: 10.1073/pnas.0911294107

Pieske, B., Houser, S. R., Hasenfuss, G., and Bers, D. M. (2003). Sodium and the heart: a hidden key factor in cardiac regulation. Cardiovasc. Res. 57, 871-872. doi: 10.1016/S0008-6363(02)00849-0

Pless, S. A., Galpin, J. D., Niciforovic, A. P., and Ahern, C. A. (2011). Contributions of counter-charge in a potassium channel voltage-sensor domain. Nat. Chem. Biol. 7, 617-623. doi: 10.1038/nchembio.622

Possani, L. D., Becerril, B., Delepierre, M., and Tytgat, J. (1999). Scorpion toxins specific for Na+-channels. Eur. J. Biochem. 264, 287-300. doi: 10.1046/j.14321327.1999.00625.x

Ramsey, I. S., Moran, M. M., Chong, J. A., and Clapham, D. E. (2006). A voltage-gated proton-selective channel lacking the pore domain. Nature 440, 1213-1216. doi: 10.1038/nature04700

Richardson, P., Mckenna, W., Bristow, M., Maisch, B., Mautner, B., O'connell, J., et al. (1996). Report of the 1995 World Health Organization/International Society and Federation of Cardiology Task Force on the Definition and Classification of cardiomyopathies. Circulation 93, 841-842. doi: 10.1161/01.CIR.93.5.841 
Rudel, R., Lehmann-Horn, F., Ricker, K., and Kuther, G. (1984). Hypokalemic periodic paralysis: in vitro investigation of muscle fiber membrane parameters. Muscle Nerve 7, 110-120. doi: 10.1002/mus.880070205

Sasaki, M., Takagi, M., and Okamura, Y. (2006). A voltage sensor-domain protein is a voltage-gated proton channel. Science 312, 589-592. doi: $10.1126 /$ science. 1122352

Scalmani, P., Rusconi, R., Armatura, E., Zara, F., Avanzini, G., Franceschetti, S. et al. (2006). Effects in neocortical neurons of mutations of the $\mathrm{Na}(\mathrm{v}) 1.2 \mathrm{Na}+$ channel causing benign familial neonatal-infantile seizures. J. Neurosci. 26, 10100-10109. doi: 10.1523/JNEUROSCI.2476-06.2006

Schroeder, B. C., Kubisch, C., Stein, V., and Jentsch, T. J. (1998). Moderate loss of function of cyclic-AMP-modulated KCNQ2/KCNQ3 K+ channels causes epilepsy. Nature 396, 687-690. doi: 10.1038/25367

Sievers, F., Wilm, A., Dineen, D., Gibson, T. J., Karplus, K., Li, W., et al. (2011). Fast, scalable generation of high-quality protein multiple sequence alignments using Clustal Omega. Mol. Syst. Biol. 7, 539. doi: 10.1038/msb.2011.75

Sigworth, F. J. (1980). The variance of sodium current fluctuations at the node of Ranvier. J. Physiol. 307, 97-129.

Sokolov, S., Scheuer, T., and Catterall, W. A. (2007). Gating pore current in an inherited ion channelopathy. Nature 446, 76-78. doi: 10.1038/nature05598

Sokolov, S., Scheuer, T., and Catterall, W. A. (2008). Depolarization-activated gating pore current conducted by mutant sodium channels in potassiumsensitive normokalemic periodic paralysis. Proc. Natl. Acad. Sci. U.S.A. 105, 19980-19985. doi: 10.1073/pnas.0810562105

Sokolov, S., Scheuer, T., and Catterall, W. A. (2010). Ion permeation and block of the gating pore in the voltage sensor of NaV1.4 channels with hypokalemic periodic paralysis mutations. J. Gen. Physiol. 136, 225-236. doi: 10.1085/jgp.201010414

Starace, D. M., and Bezanilla, F. (2001). Histidine scanning mutagenesis of basic residues of the S4 segment of the shaker k+ channel. J. Gen. Physiol. 117, 469-490. doi: 10.1085/jgp.117.5.469

Starace, D. M., and Bezanilla, F. (2004). A proton pore in a potassium channel voltage sensor reveals a focused electric field. Nature 427, 548-553. doi: 10.1038 /nature 02270

Sternberg, D., Maisonobe, T., Jurkat-Rott, K., Nicole, S., Launay, E., Chauveau, D., et al. (2001). Hypokalaemic periodic paralysis type 2 caused by mutations at codon 672 in the muscle sodium channel gene SCN4A. Brain 124, 1091-1099. doi: 10.1093/brain/124.6.1091

Stevens, M., Peigneur, S., and Tytgat, J. (2011). Neurotoxins and their binding areas on voltage-gated sodium channels. Front. Pharmacol. 2:71. doi: 10.3389/fphar.2011.00071

Striessnig, J., Bolz, H. J., and Koschak, A. (2010). Channelopathies in Cav1.1, Cav1.3, and Cav1.4 voltage-gated L-type Ca2+ channels. Pflugers Arch 460 361-374. doi: 10.1007/s00424-010-0800-x

Struyk, A. F., and Cannon, S. C. (2007). A Na+ channel mutation linked to hypokalemic periodic paralysis exposes a proton-selective gating pore. J. Gen. Physiol. 130, 11-20. doi: 10.1085/jgp.200709755

Struyk, A. F., Markin, V. S., Francis, D., and Cannon, S. C. (2008). Gating pore currents in DIIS4 mutations of NaV1.4 associated with periodic paralysis: saturation of ion flux and implications for disease pathogenesis. J. Gen. Physiol. 132, 447-464. doi: 10.1085/jgp.200809967

Sung, C. C., Cheng, C. J., Lo, Y. F., Lin, M. S., Yang, S. S., Hsu, Y. C., et al. (2012). Genotype and phenotype analysis of patients with sporadic periodic paralysis. Am. J. Med. Sci. 343, 281-285. doi: 10.1097/MAJ.0b013e31822b430c

Tao, X., Lee, A., Limapichat, W., Dougherty, D. A., and Mackinnon, R. (2010). A gating charge transfer center in voltage sensors. Science 328, 67-73. doi: 10.1126/science.1185954

Taylor, M. R., Carniel, E., and Mestroni, L. (2006). Cardiomyopathy, familial dilated. Orphanet. J. Rare Dis. 1, 27. doi: 10.1186/1750-1172-1-27

Tombola, F., Pathak, M. M., Gorostiza, P., and Isacoff, E. Y. (2007). The twisted ionpermeation pathway of a resting voltage-sensing domain. Nature 445, 546-549. doi: 10.1038/nature05396

Tombola, F., Pathak, M. M., and Isacoff, E. Y. (2005). Voltage-sensing arginines in a potassium channel permeate and occlude cation-selective pores. Neuron 45 379-388. doi: 10.1016/j.neuron.2004.12.047

Tricarico, D., and Camerino, D. C. (2011). Recent advances in the pathogenesis and drug action in periodic paralyses and related channelopathies. Front. Pharmacol. 2:8. doi: 10.3389/fphar. 2011.00008
Valiyaveetil, F. I., Sekedat, M., Mackinnon, R., and Muir, T. W. (2006). Structural and functional consequences of an amide-to-ester substitution in the selectivity filter of a potassium channel. J. Am. Chem. Soc. 128, 11591-11599. doi: 10.1021/ja0631955

Vicart, S., Sternberg, D., Fournier, E., Ochsner, F., Laforet, P., Kuntzer, T., et al. (2004). New mutations of SCN4A cause a potassium-sensitive normokalemic periodic paralysis. Neurology 63, 2120-2127. doi: 10.1212/01.WNL.0000145768.09934.EC

Wang, D. W., Desai, R. R., Crotti, L., Arnestad, M., Insolia, R., Pedrazzini, M. et al. (2007). Cardiac sodium channel dysfunction in sudden infant death syndrome. Circulation 115, 368-376. doi: 10.1161/CIRCULATIONAHA.106. 646513

Watanabe, H., Nogami, A., Ohkubo, K., Kawata, H., Hayashi, Y., Ishikawa T., et al. (2011). Electrocardiographic characteristics and SCN5A mutations in idiopathic ventricular fibrillation associated with early repolarization. Circ. Arrhythm. Electrophysiol. 4, 874-881. doi: 10.1161/CIRCEP.111. 963983

Wu, F., Mi, W., Burns, D. K., Fu, Y., Gray, H. F., Struyk, A. F., et al. (2011). A sodium channel knockin mutant (NaV1.4-R669H) mouse model of hypokalemic periodic paralysis. J. Clin. Invest. 121, 4082-4094. doi: 10.1172/JCI57398

Wu, F., Mi, W., Hernandez-Ochoa, E. O., Burns, D. K., Fu, Y., Gray, H. F., et al. (2012). A calcium channel mutant mouse model of hypokalemic periodic paralysis. J. Clin. Invest. 122, 4580-4591. doi: 10.1172/JCI6609

Wuttke, T. V., Jurkat-Rott, K., Paulus, W., Garncarek, M., Lehmann-Horn, F., and Lerche, H. (2007). Peripheral nerve hyperexcitability due to dominant-negative KCNQ2 mutations. Neurology 69, 2045-2053. doi: 10.1212/01.wnl.0000275523.95103.36

Xiao, Y., Bingham, J. P., Zhu, W., Moczydlowski, E., Liang, S., and Cummins, T. R. (2008). Tarantula huwentoxin-IV inhibits neuronal sodium channels by binding to receptor site 4 and trapping the domain ii voltage sensor in the closed configuration. J. Biol. Chem. 283, 27300-27313. doi: 10.1074/jbc.M708447200

Yang, N., George, A. L. Jr., and Horn, R. (1996). Molecular basis of charge movement in voltage-gated sodium channels. Neuron 16, 113-122. doi: 10.1016/S0896-6273(00)80028-8

Yang, N., and Horn, R. (1995). Evidence for voltage-dependent S4 movement in sodium channels. Neuron 15, 213-218. doi: 10.1016/0896-6273 (95) 90078-0

Yu, F. H., and Catterall, W. A. (2004). The VGL-chanome: a protein superfamily specialized for electrical signaling and ionic homeostasis. Sci. STKE 2004, re15. doi: 10.1126/stke.2532004re15

Yu, F. H., Yarov-Yarovoy, V., Gutman, G. A., and Catterall, W. A. (2005). Overview of molecular relationships in the voltage-gated ion channel superfamily. Pharmacol. Rev. 57, 387-395. doi: 10.1124/pr.57.4.13

Zhang, X., Ren, W., Decaen, P., Yan, C., Tao, X., Tang, L., et al. (2012). Crystal structure of an orthologue of the $\mathrm{NaChBac}$ voltage-gated sodium channel. Nature 486, 130-134. doi: 10.1038/nature11054

Zhang, X. Y., Wen, J., Yang, W., Wang, C., Gao, L., Zheng, L. H., et al. (2013). Gain-of-function mutations in SCN11A cause familial episodic pain. Am. J. Hum. Genet. 93, 957-966. doi: 10.1016/j.ajhg.2013.09.016

Conflict of Interest Statement: The authors declare that the research was conducted in the absence of any commercial or financial relationships that could be construed as a potential conflict of interest.

Received: 09 February 2014; paper pending published: 03 March 2014; accepted: 12 March 2014; published online: 03 April 2014.

Citation: Moreau A, Gosselin-Badaroudine P and Chahine M (2014) Biophysics, pathophysiology, and pharmacology of ion channel gating pores. Front. Pharmacol. 5:53. doi: 10.3389/fphar.2014.00053

This article was submitted to Pharmacology of Ion Channels and Channelopathies, a section of the journal Frontiers in Pharmacology.

Copyright (c) 2014 Moreau, Gosselin-Badaroudine and Chahine. This is an openaccess article distributed under the terms of the Creative Commons Attribution License (CC BY). The use, distribution or reproduction in other forums is permitted, provided the original author(s) or licensor are credited and that the original publication in this journal is cited, in accordance with accepted academic practice. No use, distribution or reproduction is permitted which does not comply with these terms. 